\title{
Review Article \\ Nrf2 and Notch Signaling in Lung Cancer: Near the Crossroad
}

\author{
Angelo Sparaneo, Federico Pio Fabrizio, and Lucia Anna Muscarella \\ Laboratory of Oncology, IRCCS “Casa Sollievo della Sofferenza” Hospital, San Giovanni Rotondo, Italy \\ Correspondence should be addressed to Lucia Anna Muscarella; 1.muscarella@operapadrepio.it
}

Received 4 April 2016; Revised 8 July 2016; Accepted 20 September 2016

Academic Editor: Kum Kum Khanna

Copyright (C) 2016 Angelo Sparaneo et al. This is an open access article distributed under the Creative Commons Attribution License, which permits unrestricted use, distribution, and reproduction in any medium, provided the original work is properly cited.

\begin{abstract}
The transcription factor Nrf2 (NF-E2 related factor 2) is a master regulator of the cell antioxidant response associated with tumor growth and resistance to cytotoxic treatments. In particular, Nrf2 induces upregulation of cytoprotective genes by interacting with the closely situated AREs (Antioxidant Response Elements) in response to endogenous or exogenous stress stimuli and takes part to several oncogenic signaling pathways. Among these, the crosstalk with Notch pathway has been shown to enhance cytoprotection and maintenance of cellular homeostasis, tissue organization by modulating cell proliferation kinetics, and stem cell self-renewal in several organs. The role of Notch and Nrf2 related pathways in tumorigenesis is highly variable and when they are both abnormally activated they can synergistically cause neoplastic proliferation by promoting cell survival, differentiation, invasion, and metastases. NFE2L2, KEAP1, and NOTCH genes family appear in the list of significantly mutated genes in tumors in both combined and individual sets, supporting the crucial role that the aberrant Nrf2-Notch crosstalk might have in cancerogenesis. In this review, we summarize current knowledge about the alterations of Nrf2 and Notch pathways and their reciprocal transcriptional regulation throughout tumorigenesis and progression of lung tumors, supporting the potentiality of putative biomarkers and therapeutic targets.
\end{abstract}

\section{Introduction}

Notch receptors (Notch1-Notch4) are a family of transmembrane proteins which interact with ligands of the Delta and/or Jagged/Serrate family. These receptors play a key role in the normal development of tissues and cell types, through diverse effects on differentiation, survival, and proliferation [1-3]. In tumors, Notch signaling has been observed to exert either oncogenic or antiproliferative effects within the mechanisms of cell invasion and metastases development.

The Nrf2 is a key regulator of the cell adaptive response to reactive oxygen species (ROS) and xenobiotics through the interaction with its master negative regulator, the Keap1 protein. Currently, the dark side of Nrf2 has emerged and growing evidences suggest that constitutive upregulation of Nrf2 is linked to cancer development and progression and contributes to chemo- and radioresistance.

Notch and Nrf2 are both transcription factors and their related pathways were discovered independently [4]. However, recent data have demonstrated the existence of a Nrf2Notch crosstalk which supports cytoprotection and improves maintenance of cellular homeostasis and tissue organization. This review will mainly focus on the available scientific data which underlie the biological relevance of Nrf2 and Notch pathways and their crosstalk in lung tumors and suggest the potentiality of molecularly targeted agent combinations to overcome resistance to therapies.

\section{Notch Signaling}

NOTCH genes encode for highly conserved cell membrane receptors from Drosophila to humans that orchestrate a complex signaling pathway involving a number of ligands, negative and positive modifiers, and transcription factors [5]. In mammals, four Notch receptors (Notchl to Notch4) and two families of Notch ligands (Jagged1 and Jagged2 and Deltalike-1, Delta-like-3, and Delta-like-4) have been described to play a critical role in the cell-contact-dependent cellular communications $[2,3,6]$.

Although the overall structure of Notch receptors is similar, there are significant differences in the protein domains. The Notch1-4 receptors share an extracellular portion which 


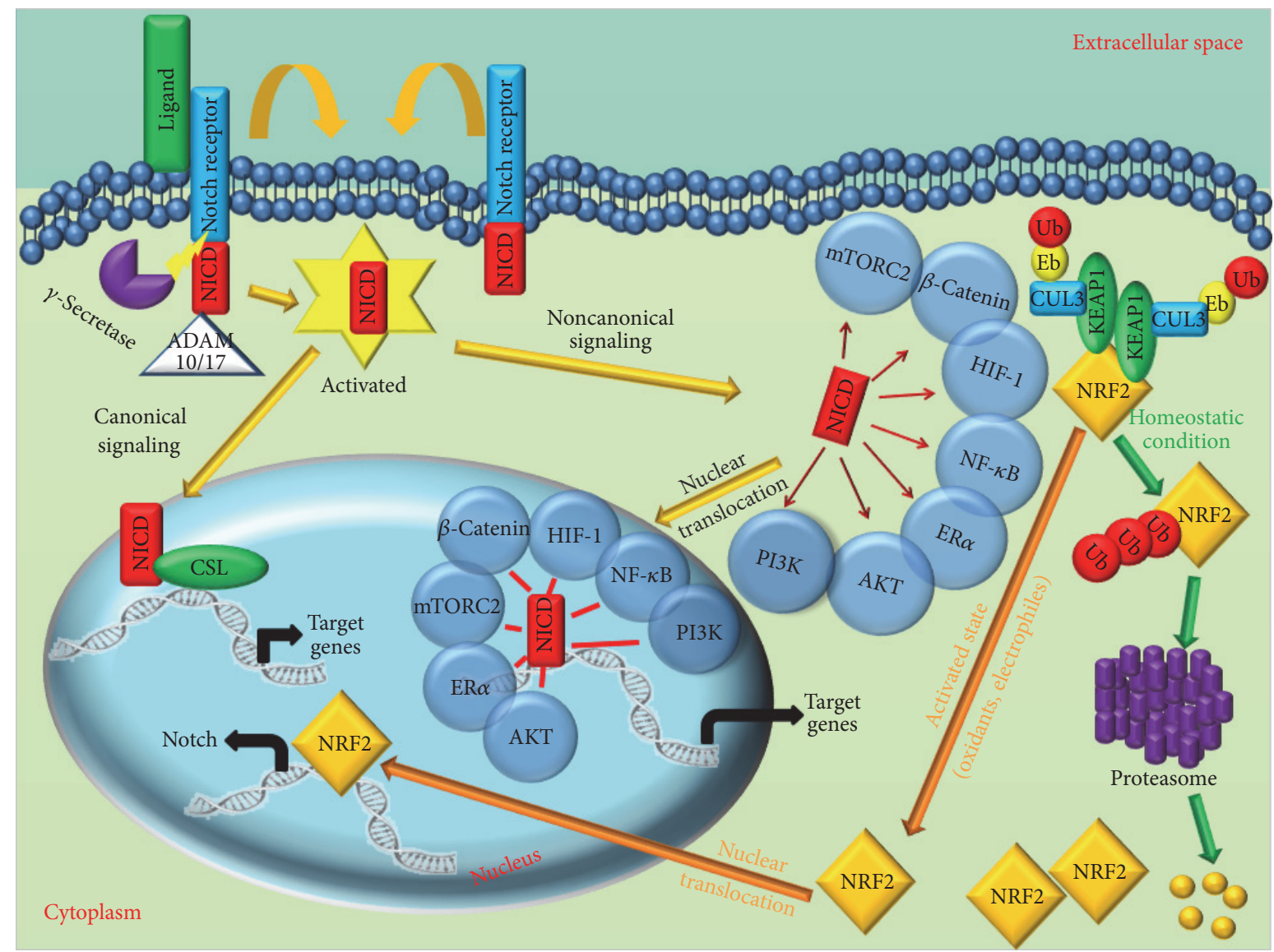

FIGURE 1: Canonical and noncanonical Notch signaling pathways. Notch signaling has a pleiotropic effect and is involved in cell survival, cell proliferation, cell metabolism, and differentiation. Canonical Notch pathway is primed by interaction of the Notch protein with a cell bound ligand. Upon interaction, Notch results cleaved, firstly by ADAM 10/17 protease and then by cleavage by the $\gamma$ - secretase. Furthermore, Notch activated (NICD) translocates into nucleus and interacts with CSL protein, where, upon interaction, the proteins complex is converted into a transcriptional activator of targets genes. Noncanonical Notch pathways may be activated either dependently or independently of ligand interaction and may be $\gamma$-secretase dependent or independent. Noncanonical Notch signaling interacts with mTORC2, AKT, Wnt, $\mathrm{HIF}-1 \alpha, \mathrm{NF} \kappa \mathrm{B}$, and PI3K pathways at either the cytoplasmic or nuclear levels. The gene regulatory region of the major Notch1 transcript has been described to possess a functional ARE through which Nrf2 can regulate Notch1 gene expression. In the activated state (orange arrow, transient upon stress stimuli or constitutive due to mutations in tumor cells), de novo synthesized Nrf2 protein accumulates into the nucleus, where it activates the transcription of several ARE-genes, including NOTCH1. In the basal state (green arrow), Keap1 binds Nrf2 and induces its ubiquitination. Upon ubiquitination, Nrf2 is degraded by proteasome complex.

contains a variable number of epidermal growth factor(EGF-) like repeats: the Notch1 and Notch2 receptors contain 36 EGF repeats, whereas Notch3 contains 34 repeats and Notch 4 contains 29 repeats. The other difference is in the transactivation domain (TAD). Notch1 and Notch2 contain a strong and a weak TAD, respectively, Notch3 has a potent but specific TAD best suited to the activation of the HES5 promoter. In contrast, Notch 4 does not contain a TAD. These structural differences may offer clues to the functional divergence among mammalian Notch paralogs [7].

The EGF-like repeats of extracellular portion of Notch are essential for ligand binding. The bond between ligands and extracellular Notch domains activates the intracellular portion and promotes intracellular sequential proteolytic cleavages by a metalloproteases of ADAM's family. Then the Notch intracellular domain (NICD) is released from the cytoplasmic membrane and translocates as active form into the nucleus, where it enhances the expression of several target genes encoding for Hairy Enhancer of Split (HES) family proteins, HES-related proteins (HEY), and p21cip1/wafl, cyclin D1 and 3, c-myc, and Her2, in a cell-context-dependent manner $[3,8,9]$.

Beside this canonical pathway activation, additional noncanonical Notch signaling pathways have been described. These additional pathways are independent from CSL (CBF1, Suppressor of Hairless, and Lag-1) transcription factor and related to other different transcription factors, such as beta-catenin, HIF-1a (hypoxia-inducible factor-1a), NF-kB (nuclear factor kappa-light-chain-enhancer of activated $\mathrm{B}$ cells), and estrogen receptor ER $\alpha$ (Figure 1) [10-13].

The Notch transcriptional machinery and signaling pathway are conserved among species, but in mammals this 
system shows the peculiarity to induce several, even opposite, biological effects depending on specific tissue types $[4,14]$. Notch signaling networks can regulate a wide range of events in embryonic and postnatal development, including proliferation, apoptosis, border formation, and cell fate decisions. Aberrant expression of Notch receptors and Notch target genes have been reported in different human malignancies, including lung, skin, pancreas, breast, and colon cancers [1520]. In lung tumors, depending on the subtype or specific molecular profiles, Notch family activity is often deregulated and activates several oncogenic pathways via direct or indirect induction $[21,22]$.

In a transgenic mouse model, Notchl was overexpressed in the alveolar epithelium and induced alveolar hyperplasia and pulmonary adenomas through regulating type II lung epithelial cells. Moreover, the concomitant expression of MYC led to a progression to adenocarcinoma and metastases, indicating a synergistic effect between Notchl and other oncogenes [23]. It has also been reported that Notch1 signaling plays a central role in the negative modulation of cell growth in lung adenocarcinoma through the ADAM metalloproteases and promotes apoptosis escape through a negative modulation of the p53 stability at protein level. These findings might explain the correlation between Notch1 activation and poor prognosis in NSCLC patients without TP53 mutations [24-28]. Few data have been provided so far concerning the roles of Notch1 in lung adenocarcinoma harboring mutations in other lung cancer driver genes, such as PIK3CA or EGFR (Epidermal Growth Factor Receptor). In NSCLC cell lines, it has been preliminary observed that the expression of the active form of Notchl (NICD1) leads to increased proliferation activity, malignant transformation, and tumor growth in presence of EGF (Epidermal Growth Factor), suggesting that EGFR activation may be essential for Notch-mediated malignant transformation and tumor growth [25].

Notchl signaling has been shown to also act either as a negative or as a positive regulator of Phosphatase and Tensin Homologue gene (PTEN) transcription [29]. PTEN downregulation is modulated by Notchl through the activation of the transcription factor hair and enhancer of SPLIT (HES1), whereas PTEN upregulation derives from the inhibition of the binding protein suppressor of hairless (RBPJ), also known as CBF-1 [30-32]. In NSCLC and malignant mesothelioma cells, the activation of PTEN transcription by Notch1 upregulation has been observed to lead the prosurvival phosphatidylinositol 3-kinase (PI3K)/Akt/mammalian target of rapamycin (mTOR) signaling pathway [29-32].

In contrast with the role of Notch1 in promoting tumor initiation and progression, Notch 2 shows a tumor suppressive activity by mediating cell differentiation in lung carcinogenesis. This evidence was also supported by immunohistochemical analysis of human NSCLC samples showing the loss or downregulation of Notch2 compared with normal lung tissues $[33,34]$. In malignant mesothelioma (MM) cells Notch2 also appears to be diminished with a consequent decrease of toxic effects and a general benefit for cells [35]. Finally, the effect of Notch3 in lung carcinoma has been observed to be strongly dependent on cell type being a tumor suppressor in Small Cell Lung Cancer (SCLC) and a tumor promoting in NSCLC by differentially modulating cell adhesion, Epithelial Mesenchymal Transition (EMT), and cell motility [36].

Various studies have assessed the clinicopathological and prognostic value of Notch1 and Notch3 expression in NSCLC, but the results remain controversial. NSCLC tissues have significantly higher Notch1 protein levels compared to lung normal tissues, with strong variations in different studies and even within the same histotypes. Overall, Notch signaling can be suggested as a valuable biomarker to predict tumor progression in NSCLC. Overexpression of Notchl and Notch 3 has been associated with increased risk of lymph node metastasis and advanced TNM (tumor size, lymph nodes, and metastases) stages. Notch1 also represents an independent prognostic factor in surgically resected adenocarcinoma patients with a major impact in combination with VEGFA (Vascular Epidermal Growth Factor-Alpha) upregulation $[37,38]$. Future investigations might clarify the usefulness of targeting Notch signaling in specific subpopulation of NSCLC patients [39].

A key role of Notch signaling has been recently highlighted in the context of SCLC growth and resistance to therapy. Stable expression of the active form of Nocth1 in SCLC cells inhibits cell proliferation and decreases the expression of several neuroendocrine markers [40]. Moreover, alteration of Notch-Ascl1-Rb-p53 axis has been recently described as major driver of secondary transition from NSCLC to neuroendocrine phenotype and SCLC [41]. These findings provide a novel cellular mechanism for lung histology transition [42] and suggest Notch signaling reactivation as a possible therapeutic strategy for SCLC patients [43].

Finally, emerging evidences suggest that Notch signaling participates to the process of EMT, a highly coordinated process observed when epithelial cells lose some or most epithelial characteristics and acquire properties that are typical of mesenchymal cells. The transition of epithelial cells to mesenchymal cells is essential during embryogenesis and includes phenotypic changes such as loss of cellcell adhesion, loss of cell polarity, and the acquisition of migratory and invasive properties. Accumulating evidences suggest that aberrant activation of the EMT developmental program contributes to tumor initiation, invasion, metastasis, and acquisition of therapeutic resistance [44, 45]. Notch, Wnt, Hedgehog (Hh), and TGF-b pathways induce welldifferentiated epithelial cells to convert into motile mesenchymal cells in tumors via the activation of multiple EMT transcription factors, including Twist, Snail, Slug, and ZEB [46] and their deregulation correlates with poor clinical outcomes [47]. These findings corroborate the hypothesis that Notch1 and Notch3 may represent typical markers of stemlike cells indifferent solid tumors, including lung cancer [48].

\section{Mechanisms of Notch Deregulation in Cancer}

Notch receptors have been found deregulated in many tumors, and the prevalence and location of mutations within 
each Notch receptor coding gene varied considerably according to the tumor type [49]. Many identified mutations are heterozygous and correlate with a haploinsufficiency in tissue pattering and suggest that loss of a single copy functionally impairs signaling and therefore induces tumorigenesis. In general, NOTCH1 gene mutations are more frequently recognized than in the other NOTCH receptor genes. This was in part, but not entirely, due to the greater number of tumors with Notchl sequencing data. For head and neck cancer (HNSCC) and lung and breast cancers, NOTCH1 mutations were relatively recurrent $(5-15 \%)$ and clustered at or near identified important domains.

In lung cancer, the deregulation of the Notch pathway is mainly correlated with activating missense mutations mostly affecting the ligand-binding domain (EGF repeats 11 and 12) or the ankyrin domains which lead to a ligand-independent activation [50]. NOTCH1 activating mutations have been defined as a common event in human NSCLC [51] and have been correlated to poor prognosis and response to therapy in lung patients without p53 mutations [52]. To note, NOTCH1 mutations in SqCC appeared to be more frequent than pulmonary adenocarcinoma, and their typical location in close proximity of the ligand-binding domain leads to the speculation that Notchl is more likely to function as a tumor suppressor in SqCC than in the adenocarcinoma histology [49]. However, the real frequency of NOTCH1 mutations in NSCLC remains to be determined. The limited size and intrinsic variations of the just reported studied cohorts, along with the differences in sequencing strategy, do not allow a definitive conclusion on the magnitude of this event [53].

By contrast, mutations affecting the NOTCH family genes have been widely assessed and described as one of the most mutated pathways driving neuroendocrine features and SCLC. Different missense changes affecting all NOTCH1$\mathrm{NOTCH} 4$ genes with different frequency in relation to the different histologies of lung neuroendocrine tumors have been reported [54]. In SCLC, frequent damaging mutations have been identified in the extracellular domain with an incidence of about 25\%, suggesting that Notch may act a tumor suppressor [55], leading to growth inhibition and neuroendocrine markers reduction [56].

Mutations in NOTCH1-NOTCH4 family genes (28\%) have also been recently reported in Large Cell Neuroendocrine Cancer (LCNEC) by genomic analysis. Many mutations were located in the extracellular EGF-like domain and were mainly associated with NSCLC-like subgroup but differ from the typical mutation pattern of lung adenocarcinoma. This represents an additional, strong evidence of the crucial role of Notch in lung neuroendocrine development [57].

In addition to direct mutations of NOTCH genes, alternative mechanisms of Notch deregulation have been reported in lung cancers. Molecular profiling of alternative splicing variants in lung adenocarcinoma have revealed frequent alternative splicing events affecting the $N U M B$ gene, similar to primary breast and colon cancers. These abnormal isoforms lack normal activity and aberrantly induce the reduction of Numb protein expression levels and activation of the Notch signaling pathway there by promoting cell proliferation [58].
Finally, recent evidences indicate that there is a significant crosstalk between Notch and microRNAs. As a key component of the Notch-mediated transcription complex, Notch can regulate expression of a number of microRNAs; at the same time, Notch ligands, Notch receptors, or Notch effectors are regulated by microRNAs [59]. Indeed, members of five different families of miRNAs (miR-2, miR-4, miR-7, miR-11, and miR-79) have been shown to negatively regulate Notch target genes by recognizing conserved binding motifs within their transcripts [60]. However, few evidences about the role of this epigenetic mechanism of expression regulation have been provided in lung cancer. Pharmacological induction of miR-34a decreased the expression of Notchl and its downstream targets including HES-1, Cyclin D1, Survivin, and Bcl-2, impairing Notch signaling, cell proliferation, and invasion and inducing apoptosis in NSCLC cells [61].

\section{Nrf2 Signaling}

Nrf2 is a basic region-leucine zipper (bZIP) transcription factor that acts as a master modulator of cellular protection against carcinogens and oxidative damage in organisms. Although diverse mechanisms might be involved, it is speculated that the induction of phase II cytoprotective enzymes by Nrf2 chemical inducers occurs, at least in part, by modulating the activities of intracellular signaling kinases [62]. In the cellular basal state, the majority of de novo synthesized Nrf2 is repressed by physical interaction with Keap1, which is an adaptor protein to Cullin 3- (Cul3-) dependent ubiquitination and proteasomal degradation [63-67]. When cells are exposed to exogenous and endogenous toxic substances and to oxidative damage, a specific pattern of Keapl cysteine modification arises [66]. By consequence, the Keap1 releases Nrf2 which translocates into the nucleus where it forms a heterodimer with small Maf proteins. This complex specifically recognizes enhancer sequences known as Antioxidant Response Elements (AREs), located in the regulatory regions of genes encoding for cellular defense enzymes, and activates their expression through the transcription machinery [68, 69]. Several Nrf2 target genes have been identified so far, and the number has increased through the recent technical advances [70]. Apart from the major cytoprotective functions of Nrf2 targeted genes, many of these genes also play in the context of oncogenesis, cell proliferation, apoptosis, and tumor cell growth in many cancer types (Figure 2). Recently, the involvement of Nrf2 has also been recognized in mitochondrial physiology as inductor of respiration substrates, membrane potential maintenance, integrity, and biogenesis [70-74].

Scientific findings in several neoplastic backgrounds underlined how the Nrf2 activity is clearly connected with oncogenic kinase pathways, structural proteins, hormonal regulation, other transcription factors, and epigenetic enzymes involved in the pathogenesis of tumors [75].

The large-scale genomic studies of NSCLC by The Cancer Genome Atlas (TCGA) consortium and others have supported that Nrf2 deregulation represents one of the major cancer driver pathways in the specific histotypes of SqCC 


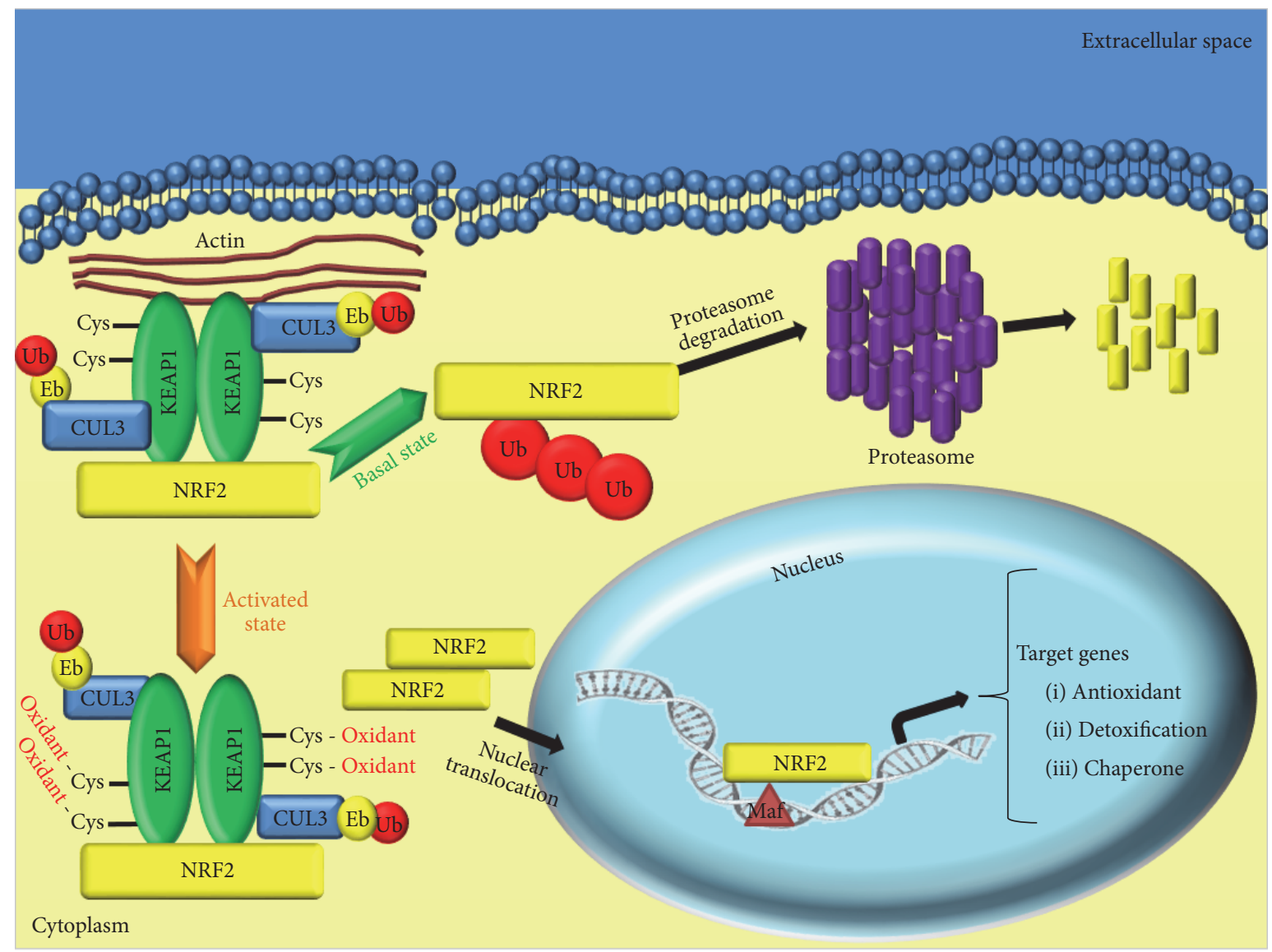

Figure 2: Keap1/Nrf2 axis in lung cancer. Under basal conditions (green arrow), Nrf2 is sequestered in the cytoplasm by the Keap1-Cul3 complex and rapidly degraded in the ubiquitin-proteasome dependent manner. This Keapl-mediated degradation activity requires two reactive cysteine residues of Keapl, located into the IVR domain. Upon stress stimuli (orange arrow), modification of these cysteine residues of Keap1 inhibits ubiquitin conjugation to Nrf2 by the Keap1-Cul3 complex, thereby provoking Nrf2-Keap1 impairment and resulting in the nuclear accumulation of de novo synthesized Nrf2 protein and enhancement of target genes transcription.

where cigarette exposure can activate the oxidant stress response [76] and LCNEC of the lung with Non-SmallCell Carcinoma features $[77,78]$. Several mechanistic studies proved opposite roles of Nrf2 during carcinogenesis, either protective or promoting malignant progression [79]. The latter is supported by many clinical observations showing that constitutive upregulation is strongly associated with cancer development, progression, and resistance to conventional chemotherapy and radiotherapy in NSCLC [79-82]. Measuring nuclear Nrf2 abundance in NSCLC patients might be a useful index to predict the efficacy of platinum-based treatments. Nuclear accumulation of Nrf2 correlated with worse NSCLC cancer-specific survival and worse progressfree survival in three independent datasets of SqCC patients treated with surgery only [83-85]. As the main negative regulator of Nrf2, Keap1 activity and impairment also correlated with NSCLC survival. Our group discovered that NSCLC patients harboring KEAP1 alterations had worse progressionfree survival compared with other patients [86]. Similarly, Takahashi et al. found that KEAP1 mutations caused an increase of Nrf2 expression in NSCLC patients and were correlated with worse progression-free and overall survival [87].

Along with KEAP1 mutations, the expression levels of two Nrf2 downstream transcripts expressions, Ho-1 $[88,89]$ and Nqo1 [90-92], were found significantly associated with tumor invasiveness and patients survival in NSCLC advanced stage. In this regard, a recent extensive meta-analysis of microarray data for $240 \mathrm{Nrf2}$-mediated genes expression signature identify a group of 50 genes (NFE2L2-associated molecular signature, NAMS) that predicts a worse clinical outcome in $60 \%$ of NSCLC cohorts analyzed. These data corroborate the idea that NAMS could represent a promising prognostic biomarker in human lung cancer [93]. Correlation of Nrf2 downstream transcripts expression with tumor invasiveness and patients survival in NSCLC advanced stage has been also reported for Ho-1 [88, 89] and Nqo1 [90-92].

Three major crosstalks between Nrf2 and other classical oncogenic signaling pathways such as phosphatidylinositol 3-kinase (PI3K) [94], Kirsten retrovirus-associated DNA sequence (K-ras), [95] and Notch [4] have been reported in lung cancer as having a strong impact on tumor resistance 
outcome. The PI3K-Akt-mTOR pathway is commonly deregulated in several human malignancies including NSCLC [96], and activated PI3K signal increased accumulation of Nrf2 into the nucleus to enhance the transcription of enzymes involved in the pentose phosphate pathway [72]. Since radiotherapy agents can effectively induce apoptosis through generation of ROS [97] it was observed that specific PI3K inhibitor such as NVP-BKM120 can be used in SqCC to decrease Nrf2 protein levels and sensitize NFE2L2 or KEAP1mutant cells to radiation [94]. KRAS gene mutations occur approximately in $20-30 \%$ of NSCLCs and confer to cancer cells resistance and survival [98, 99]. Promoter analysis showed that a TPA response element (TRE) located in exon1 of NFE2L2 gene was activated by Kras. Thus, oncogenic Kras confers in NSCLC chemoresistance by upregulating Nrf2, enhancing the antitumor efficacy of cisplatin and providing a strong preclinical rationale to improve the management of lung tumors harboring KRAS mutations with Nrf2 pathway inhibitors $[79,95,100]$.

\section{Mechanisms of Nrf2 Deregulation in Cancer}

Firstly described in NSCLC cell lines and tissues by Singh et al. in 2006, molecular impairment of Keap1/Nrf2 axis has been then extensively investigated in lung with different mutation clusters found to be related to specific histological subtypes. The overexpression of nuclear Nrf2 and the subsequent increase in the antioxidant defense in lung cancer cells are mainly related to genetic and epigenetic alterations of the KEAP1 and NFE2L2 genes [101]. Somatic mutations of the KEAP1 gene frequently affect the DC domain and produce a decrease in Keapl-promoted Nrf2 ubiquitination by $\mathrm{Cul} 3$ or the impairment of nuclear export of Nrf2 by Keap1/Cul3 complexes. In both cases, under cellular stress condition, Nrf2 escapes degradation and translocates into the nucleus to induce the expression of its target genes [102104]. Mutations in NFE2L2 gene were also widely described in lung tumors, suggesting a strong link between molecular perturbations of the Nrf2 pathway and tissue exposure to ROS [105]. NFE2L2 mutations should determine a constitutive activation and have been found to mainly cluster within the DLG and ETGE motifs, which are hotspot sites for Nrf2 binding to the Keap1 DC binding domain. In particular, the ETGE mutant proteins are not ubiquitinated and concentrate in the nucleus, whereas mutations in the DLG resulting in the stabilization of Nrf2 increased its nuclear translocation and Nrf2 de novo molecules synthesis [106, 107].

Mutations and copy number alterations of NFE2L2 and KEAP1 and/or deletion or mutation of CUL3 were observed in $25-34 \%$ of SqCC among the classical alterations associated with this smoking-related histology subtype of lung cancer $[77,84]$. Instead, a low incidence of KEAP1 mutations has been reported in advanced stage ADC patients with different ethnicity (3-19\%) and a lower incidence of EGFR mutations [108, 109], except for papillary adenocarcinoma tumors subtypes (60\%) [110]. In addition, TCGA analysis of lung adenocarcinomas has shown that the odds of a tumor carrying a KEAP1 mutation increased more than sixfold among tumors with $L K B 1$ loss. LKB1-deficient tumors are susceptible to oxidative stress because they are unable to produce the appropriate adaptive responses in metabolism and biosynthesis. The high level of overlap in loss of function of KEAP1 and LKB1 genes may suggest that selective pressure exists for the activation of Nrf2 as a secondary protective mechanism to compensate for LKB1 loss [111].

More recently, new experimental evidences have demonstrated a mutual regulation between Nrf2 and microRNAs, especially in the mechanisms of tumor chemoresistance. Indeed, several miRNAs have been validated to target Nrf2 and thus affect its signaling pathway, although only few data have been collected in lung tumor [112-115]. On the other hand, Nrf2 has been demonstrated to regulate the expression of different miRNAs. For instance, functional studies in human lung fibroblasts reported as Nrf2/miR-140 signaling confers radioprotection by inducing Nrf2 nuclear translocation and subsequent activation of miR-140 transcription [116]. Moreover, miR-200a reactivation by histone deacetylation has been reported to destabilize Keap1 transcript in resistant lung tumor cell lines [117], whereas Nrf2-dependent regulation of miR-1 and miR-206 has been described to crucially promote non-small-cell lung proliferation and tumorigenesis by modulating the pentose phosphate pathway [118].

Lately, KEAP1 alterations have emerged as an important molecular feature of neuroendocrine tumors of the lung. By performing genome/exome and transcriptome sequencing Fernandez-Cuesta et al. have demonstrated that it is possible to distinguish an LCNEC SCLC-like group, carrying MYCL1 amplifications and mutations in both RB1 and TP53 genes from an $\mathrm{AD} / \mathrm{SQ}$-like group, harboring CDKN2A deletions, TTF1 amplifications, and frequent mutations in KEAP1 and STK11. This represents a picture of an evolutionary trunk that can branch to SCLC or AD/SQ on the basis of a different genetic background [112]. These data have been confirmed by Rekhtman et al., who reported an incidence of $31 \%$ of KEAP1 mutations in LCNEC NSCLC-like subset [78].

In addition to somatic mutations, other mechanisms affecting Nrf2 expression in lung tumors have been found, even though this field still remains mostly unexplored. For instance, there are compelling evidences that epigenetic regulation might play a key role in modulating Keap1/Nrf2 axis in lung cancer cells [119]. Hypermethylation of the KEAP1 promoter region was firstly described by Wang et al. as a pivotal mechanism in the modulation of the KEAP1 mRNA expression in cell lines and primary lung tumors that could be restored by 5-Aza treatment [120]. A larger study from our group on a cohort of resected primary NSCLCs confirmed these results and further proposed the epigenetic inactivation of KEAP1 by promoter hypermethylation as the main mechanism which leads to reduced or absent Keap1 protein expression previously reported in NSCLC. Genetic and epigenetic analyses on this cohort suggest KEAP1 biallelic inactivation as molecular marker of worst prognosis [86]. It has been recently demonstrated by in vitro analysis that the methylation status of KEAP1 can also predict the tumor cells sensitivity to radiation. Importantly, when radiation is combined with the angiogenesis inhibitor Genestein, there is an increase of ROS levels and cell apoptosis via overexpression 
of Nrf2, GSS, and Ho-1 in lung adenocarcinoma cells [121]. A possible role of histone deacetylation/acetylation in the epigenetic regulation of the Keap1/Nrf2 pathway has been reported in human NSCLC, where hMOF-mediated acetylation of Nrf2 increased its nuclear retention and the transcription of its downstream genes, subsequently modulating tumor growth and drug resistance [122]. This new role of histone modification in the modulation of Nrf2 has been supported by $\mathrm{Li}$ et al., who showed that decreased Ezh2 expression significantly correlated with elevated expression of Nrf2 and its target genes, both in lung cancer tissues and in cell lines [113].

More recently, among the epigenetic mechanisms, new experimental evidences have demonstrated that miRNAs may crucially modulate the Nrf2 expression and affect its signaling pathway in a chemoresistance context [114-116, 119]. Nevertheless, most of the data have been reported in epithelial tumors such as breast and colon, whereas only few have been provided in lung cancer. On the other hand, functional studies on human lung fibroblasts reported as Nrf2/miR-140 signaling confer radioprotection by inducing Nrf2 nuclear translocation and subsequent activation of miR-140 transcription [117]. MiR-200a reactivation by histone deacetylation has been reported to destabilize Keap1 transcript in resistant lung tumor cell lines [118], whereas Nrf2-dependent regulation of miR-1 and miR-206 has described as crucial in non-small-cell lung proliferation and tumorigenesis through the modulation of the pentose phosphate pathway [123].

\section{Nrf2-Notch Pathways Crosstalk in Lung Cancer}

Nrf2, Keap1, and Notch1 rank among the first frequently mutated genes in tumors and were deemed to be significant both in the combined sets of tumors and in individual tumor types. This observation leads to the speculative general notion that the outcome from aberrant Nrf2-Notch crosstalk by molecular impairment in these genes might enhance tumorigenesis and progression to cancer [4], especially in the stem cell (SC) context.

A number of experimental models have been employed to demonstrate that Nrf2 is involved in the maintenance of the stem cell phenotype. ROS have more recently been found to have useful roles in SC proliferation and differentiation [129]. However, the functional significance of the ROS status in different types of SCs, the downstream signaling events, and the role of ROS in SC self-renewal for repair and homeostasis is controversial [130-132]. In Drosophila intestinal stem cells, loss of the CncCbZIP-CNC (cap-n-collar subfamily of basic leucine zipper) transcription factor has been reported to increase ROS levels and cell proliferation rates, suggesting that $\mathrm{CncC}$ is required to keep the intestinal stem cells in a state of quiescence and to prevent them from entering the cell cycle [130]. In mouse hematopoietic stem cells, loss of Nrf2 has been shown to lead to an expansion of the progenitor pool of myeloid and lymphoid lineages, again suggesting that Nrf2 supports stem cell renewal and proliferative quiescence [133]. A reciprocal Nrf2-Notch transcriptional regulation has been described in hepatobiliary system, having a key role in liver development and in maintenance of hepatic function and its deregulation might be one of the main pathways for promoting cancer [134-136].

Less evidences have been provided for a clear Notch-Nrf2 crosstalk in lung cancer. The airway epithelium is constantly exposed to environmental oxidants and therefore serves as an interesting model system to study redox signaling. Cigarette smoke is known to cause oxidative stress-induced airway injury [137], diseases, and cancer airway-related through well-known mechanisms [138].

Additionally, Nrf2 has been implicated in the self-renewal of human airway basal stem cells, but in this case the flux of ROS levels appeared to be the critical factor. In the same context, Notchl signaling pathway was implicated in helping dynamic changes in ROS levels [138] and has been noted to be essential in early lung development and in the regulation of stem cell self-renewal; thus, when abnormally activated these pathways can cause neoplastic proliferation, representing an early event in tumorigenesis [139]. Beside this, an inverse modulation of Notch by Nrf2 was observed. The gene regulatory region of the major Notchl transcript has been described to possess a functional ARE region through which Nrf2 can directly regulate Notch1 gene expression, thus promoting airway basal stem cells' self-renewal [138, 140]. Finally, recent data have shown that Nrf2 strongly regulates Notchl activity and promotes radiation-induced apoptosis through Nrf2 mediated Notch1 signaling in NSCLC cells. Thus, Notch signaling is an important determinant in radioresistance of lung cancer cells [141] (Figure 3).

An indirect suggestion of a functional interdependence in the Notch and Nrf2 pathways comes from recently published studies of genomic analysis in LCNECs. Genes mutation profiling revealed a high incidence of $\mathrm{NOTCH}$ genes family (33\%) and KEAP1-NFE2L2 (39\%) alterations in specific subsets of LCNECs. In particular, NOTCH genes family alterations represent one of the most relevant differences in NSCLC-like LCNEC from classic lung adenocarcinoma and are of particular interest because they give a strong evidence for their crucial role of Notch receptors in neuroendocrine fate specifications in normal and tumor development [55, 57]. However, despite the overall similarity, the most relevant differences identified in SCLC-like LCNEC were an elevated rate of KEAP1-NFE2L2 mutations that rarely occur in conventional SCLC but are frequent in SqCC, suggesting a stronger histogenetic relationship of some conventional SCLCs and SqCCs [78]. Finally, frequent cooccurring mutations NFE2L2, KEAP1, and NOTCH1 in a study on more than four thousand human cancers support the notion that the outcome from aberrant Nrf2-Notch crosstalk by mutations in these genes might specifically enhance tumorigenesis and progression to cancer [142].

\section{Therapeutic Targeting of Notch and Nrf2 Pathways}

The central role of Notch signaling in cancer, cancer stem cell maintenance, and angiogenesis has significantly fostered 


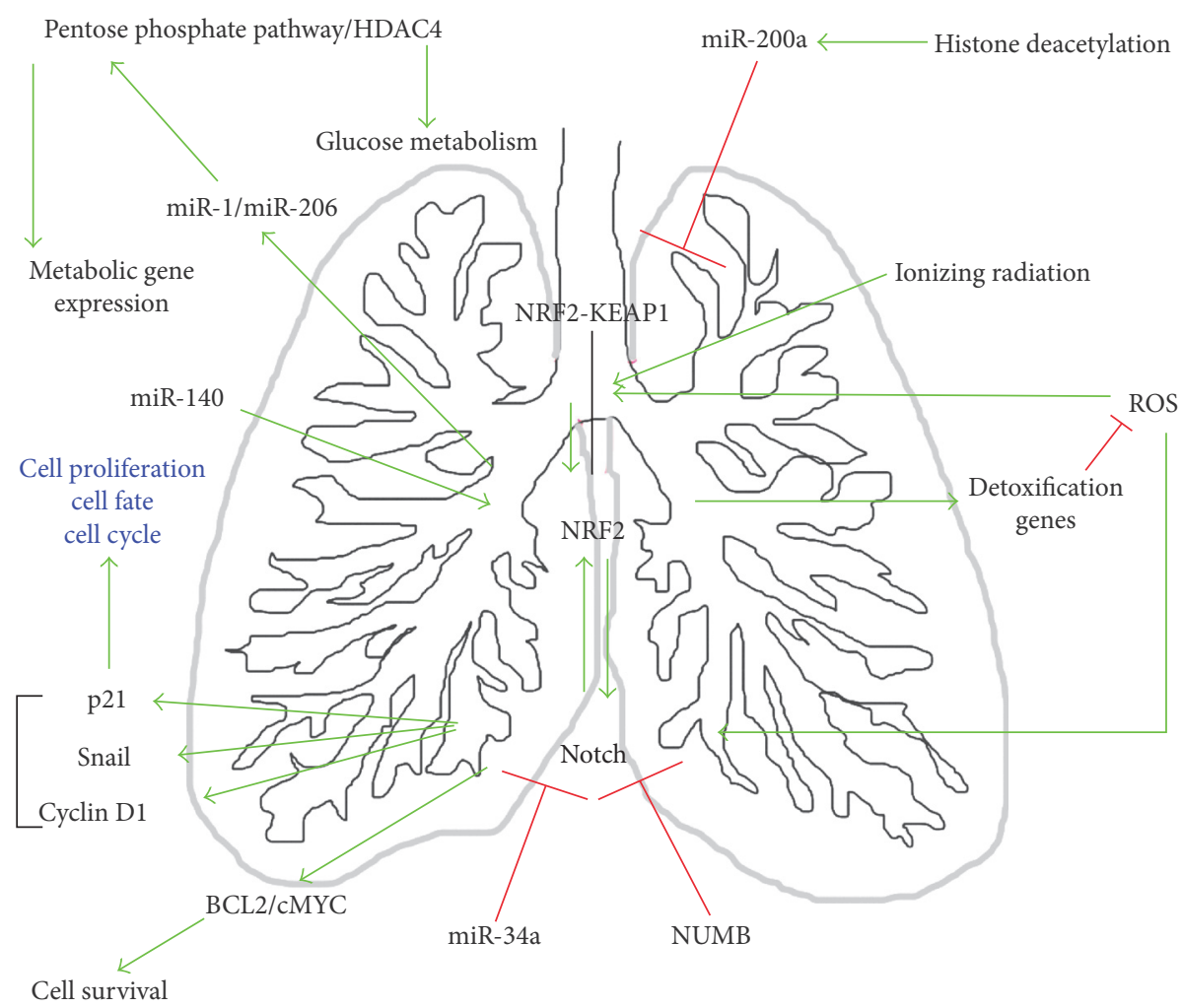

Figure 3: Integrated network of Nrf2-Notch crosstalk in lung. Links for biological events occurring in lung involving Nrf2 and Notch interaction with other signaling networks. Black lines indicate interaction, green arrows indicate activation, and red arrows indicate repression.

the transition from preclinical research into clinical application of alternative targeted compounds, including small molecule inhibitors and large mAbs (monoclonal antibodies) targeting Notch signaling [143]. At the same time, the adjuvant effect of these inhibitors in combination with current chemotherapeutics is still under evaluation in different clinical trials (Table 1) [144].

The interaction between Notch receptor(s) and ligand(s) takes place within a tight cell-to-cell compartment. Following ligand-receptor association, the sequential two-steps cleavage by the ADAM/TACE proteinase and $\gamma$-secretase, respectively, culminates in the functional activation of Notch signaling. Numerous preclinical models have documented so far the anticancer effects of different classes of compounds inhibiting Notch signaling activation such as siRNAs, GSIs, and mAbs [145], with encouraging results for clinical implementation in combination with either chemotherapy or targeted agents [146]. Among these, the oral GSI PF-0308414 showed clinical activity in a phase I study in patients with advanced stage solid tumors [147].

In this context, Notch pathway inhibition is currently under investigation as novel therapeutic option of SCLC. For instance, the fully human IgG2 antibody Tarextumab (TRXT, OMP59R5) combined with chemotherapy has been shown to significantly reduce tumor recurrence in patient-derived SCLC xenografts, by targeting Notch2/Notch3 [148]. On the strength of these results, a phase I/II study of Tarextumab in combination with six cycles of cisplatin and etoposide in ESSCLC, followed by Tarextumab maintenance (PINNACLE, NCT01859741), is currently ongoing [149].

Alternative approaches for targeting Notch signaling in lung cancer may include several natural agents, such as curcumin $\left(3,3^{\prime}\right.$-diindolylmethane, DIM), resveratrol 3,5bis (2,4-difluorobenzylidene)-4-piperidone (DiFiD), and epigallocatechin-3-gallate (EGCG) [150], whose anticancer activity has been demonstrated in both in vitro and in vivo models of other solid tumors [151, 152].

Similarly, the pharmacological inhibition of Nrf2 signaling may represent a further therapeutic strategy for cancer treatment, especially in those patients carrying increased levels of Nrf2 (Table 2). Indeed, recent reports have demonstrated that the high levels of $\mathrm{Nrf} 2$ are significantly associated to chemo- and radioresistance, rendering the development of novel Nrf2 inhibitors particularly intriguing [153]. For example, it has been demonstrated that all-trans retinoic acid (ATRA) and retinoic acid receptor- $\alpha$ (RAR $\alpha)$ agonists can directly sequester Nrf2 and prevent its binding to the ARE, leading to the global downregulation of Nrf2-dependent gene expression [154]. Similar outcomes have been reported as a result of the physical blocking of Nrf2 operated by other nuclear receptors, such as peroxisome proliferator-activated receptor- $\gamma(\operatorname{PPAR} \gamma)$, estrogen receptor- $\alpha(\mathrm{ER} \alpha)$, estrogenrelated receptor $\beta$ (ERR $\beta)$, and glucocorticoid receptor (GR) [155]. 


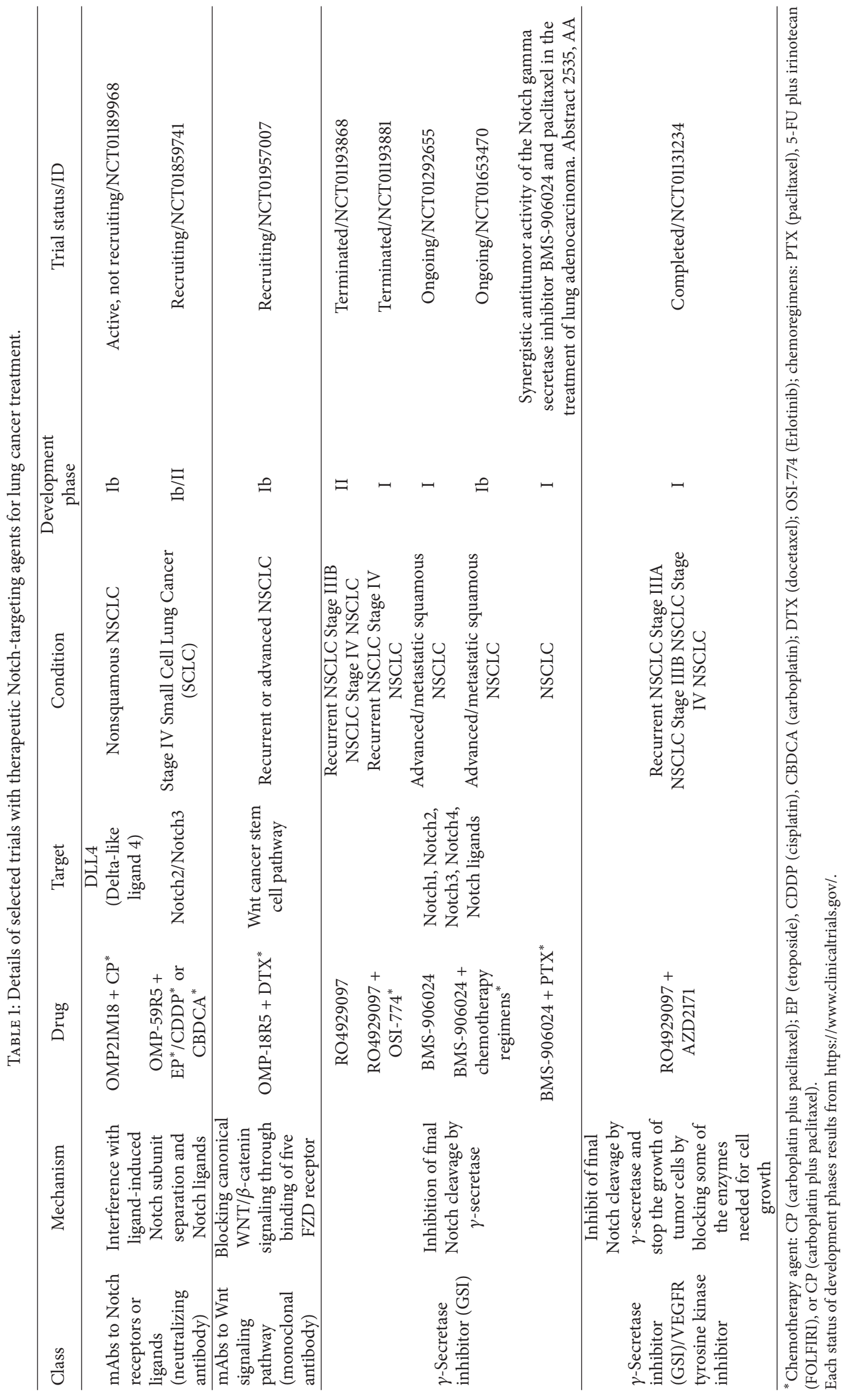


TABLE 2: Details of selected trials or scientific reports on therapeutic Nrf2-inhibition for lung cancer treatment.

\begin{tabular}{|c|c|c|c|c|c|c|}
\hline Class & Mechanism & Drug & Target & Condition & $\begin{array}{l}\text { Development } \\
\text { phase }\end{array}$ & Trial status/ID or scientific reports \\
\hline \multirow{4}{*}{$\begin{array}{l}\text { Vitamin A } \\
\text { metabolite }\end{array}$} & $\begin{array}{l}\text { All-trans retinoic } \\
\text { inhibits the basal } \\
\text { and inducible } \\
\text { activity of Nrf2 }\end{array}$ & $\begin{array}{c}13-\mathrm{CRA} \\
+\mathrm{IFN}_{-}^{+} \mathrm{A}^{+}\end{array}$ & \multirow{4}{*}{$\begin{array}{l}\text { Retinoid X } \\
\text { receptor } \\
\text { alpha binding } \\
\text { to Neh7 } \\
\text { domain of } \\
\text { Nrf2 }\end{array}$} & $\begin{array}{l}\text { Recurrent } \\
\text { Squamous } \\
\text { Cell Lung } \\
\text { Cancer } \\
\text { (SqCC) }\end{array}$ & II & Completed/NCT00002506 \\
\hline & \multirow{3}{*}{$\begin{array}{l}\text { RAR-alpha } \\
\text { complex (with } \\
\text { Nrf2) is not able } \\
\text { to bind to ARE } \\
\text { and decreases } \\
\text { the Nrf2 ability } \\
\text { to activate } \\
\text { ARE-driven } \\
\text { genes }\end{array}$} & $\begin{array}{l}\text { ATRA + } \\
\text { CDDP* }^{*} \\
+ \text { MTC }^{*} \\
+ \text { NVB }^{*}\end{array}$ & & $\begin{array}{l}\text { Stage IIIB } \\
\text { or IV } \\
\text { NSCLC }\end{array}$ & II & Unknown/NCT00005825 \\
\hline & & $\begin{array}{l}\text { 13-CRA } \\
+ \text { IFN-A }^{+} \\
+ \text {PTX }^{*}\end{array}$ & & $\begin{array}{l}\text { Recurrent } \\
\text { Small Cell } \\
\text { Lung } \\
\text { Cancer } \\
\text { (SCLC) }\end{array}$ & II & Completed/NCT00062010 \\
\hline & & $\begin{array}{l}\text { ATRA + } \\
\text { PCB }^{* * *}\end{array}$ & & $\begin{array}{l}\text { Stage IIIB } \\
\text { or IV } \\
\text { NSCLC }^{* *}\end{array}$ & II & Completed/NCT01048645 \\
\hline Quinoid diterpene & $\begin{array}{c}\text { Inducing } \\
\text { apoptosis by } \\
\text { sensitizing } \\
\text { A549/DDP cell } \\
\text { and inhibiting } \\
\text { Nrf2 pathway in } \\
\text { chemoresistant } \\
\text { lung carcinoma }\end{array}$ & $\begin{array}{l}\mathrm{CTS}+ \\
\mathrm{CDDP}^{*}\end{array}$ & $\begin{array}{l}\text { Inhibitor of } \\
\text { STAT3 and } \\
\text { AChE }\end{array}$ & $\begin{array}{l}\text { A549/DDP } \\
\text { cell line }\end{array}$ & $\begin{array}{l}\text { In vitro and } \\
\text { in vivo }\end{array}$ & $\begin{array}{l}\text { Xia et al., } 2015 \text { [124], Cell } \\
\text { PhysiolBiochem }\end{array}$ \\
\hline \multirow[b]{2}{*}{ Flavonoid } & $\begin{array}{c}\text { Inhibiting } \\
\text { ARE-driven gene } \\
\text { expression redox- } \\
\text { independently, } \\
\text { leading to a } \\
\text { dramatic decrease } \\
\text { in Nrf2 protein } \\
\text { levels with } \\
\text { depletion of } \\
\text { reduced } \\
\text { glutathione }\end{array}$ & LUT & & $\begin{array}{l}\text { A549 } \\
\text { adenocar- } \\
\text { cinoma } \\
\text { cell line }\end{array}$ & $\begin{array}{l}\text { In vitro and } \\
\text { in vivo }\end{array}$ & $\begin{array}{c}\text { Tang et al., } 2011 \text { [125], Free Radical } \\
\text { Biology \& Medicine }\end{array}$ \\
\hline & $\begin{array}{l}\text { Cell proliferation, } \\
\text { the expression of } \\
\text { Nrf2, and } \\
\text { antioxidant } \\
\text { enzyme were all } \\
\text { reduced in tumor } \\
\text { xenograft tissues } \\
\text { after cotreatment } \\
\text { and inhibiting } \\
\text { tumor cell growth }\end{array}$ & $\begin{array}{l}\mathrm{LUT}+ \\
\mathrm{CDDP}^{*}\end{array}$ & $\begin{array}{l}\text { SRC tyrosine } \\
\text { kinase }\end{array}$ & $\begin{array}{l}\text { A549 cell } \\
\text { line in } \\
\text { athymic } \\
\text { nude mice }\end{array}$ & $\begin{array}{l}\text { In vitro and } \\
\text { in vivo }\end{array}$ & $\begin{array}{c}\text { Chian et al., } 2014 \text { [126], Biochemical } \\
\text { and Biophysical Research } \\
\text { Communication }\end{array}$ \\
\hline $\begin{array}{l}\text { Glycopeptide } \\
\text { antibiotic }\end{array}$ & $\begin{array}{l}\text { Involveing } \\
\text { suppression of } \\
\text { Nrf2 activation, } \\
\text { inhibiting the } \\
\text { incorporation of } \\
\text { thymidine into } \\
\text { DNA strand, and } \\
\text { causing cell cycle } \\
\text { arrest in G2 and } \\
\text { in mitosis }\end{array}$ & $\begin{array}{l}\mathrm{BLM}+ \\
\mathrm{CDDP}^{*} \\
+5-\mathrm{FU}^{*} \\
+\end{array}$ & $\begin{array}{l}\text { Synthesis of } \\
\text { nucleic acid }\end{array}$ & $\begin{array}{c}\text { A549 } \\
\text { adenocar- } \\
\text { cinoma } \\
\text { cell line } \\
\text { LC-AI } \\
\text { squamous } \\
\text { cell line } \\
\text { NCI-H292 } \\
\text { mucoepi- } \\
\text { dermoid } \\
\text { cell line }\end{array}$ & In vitro & $\begin{array}{c}\text { Homma et al., } 2009 \text { [127], Clin } \\
\text { Cancer Res }\end{array}$ \\
\hline
\end{tabular}


TABLE 2: Continued.

\begin{tabular}{|c|c|c|c|c|c|c|}
\hline Class & Mechanism & Drug & Target & Condition & $\begin{array}{l}\text { Development } \\
\text { phase }\end{array}$ & Trial status/ID or scientific reports \\
\hline Quassinoids & $\begin{array}{l}\text { Inhibiting the } \\
\text { Nrf2-mediated } \\
\text { protective } \\
\text { response at } \\
\text { subnanomolar } \\
\text { concentration, } \\
\text { increase } \\
\text { ubiquitination, } \\
\text { enhancing Nrf2 } \\
\text { degradation, and } \\
\text { reducing Nrf2 } \\
\text { protein levels } \\
\text { Cotreatment } \\
\text { inhibits the Nrf2 } \\
\text { protective } \\
\text { mechanism, leads } \\
\text { to decreases cell } \\
\text { proliferation, } \\
\text { enhances } \\
\text { oxidative DNA } \\
\text { damage, and } \\
\text { reduces apoptosis }\end{array}$ & Brusatol & $\begin{array}{l}\text { Formation of } \\
\text { the first } \\
\text { peptide bond } \\
\text { between } \\
\text { puromycin } \\
\text { and } \\
\text { methionyl- } \\
\text { transfer } \\
\text { RNA }\end{array}$ & $\begin{array}{l}\text { Cell } \\
\text { culture } \\
\text { and } \\
\text { murine } \\
\text { A549 } \\
\text { xenograft } \\
\text { models }\end{array}$ & $\begin{array}{l}\text { In vitro and } \\
\text { in vivo }\end{array}$ & $\begin{array}{l}\text { Vartanian et al., } 2016 \text { [128], } \\
\text { Molecular \& Cellular Proteomics }\end{array}$ \\
\hline
\end{tabular}

AA panel of Nrf2 inhibitor cited in the table as follows: 13-CRA (13-cis-retinoic acid), ATRA (all-trans retinoic acid); CTS (cryptotanshinone); LUT (luteolin); BLM (bleomycin); brusatol.

${ }^{+}$Biological agent: IFN-A (interferon alpha).

* Chemotherapy agent: CDDP (cisplatin), MTC (mitomycin C), NVB (vinorelbine tartrate); PTX (paclitaxel); 5-FU (fluorouracil).

** In this study patients that have already received paclitaxel and cisplatin $(\mathrm{PC})$ were recruited.

*** PCB (placebo) means an innocuous medication given to the control group in experiments on the efficacy of a drug.

Each status of development phases results from https://www.clinicaltrials.gov/.

An increasing number of natural compounds are known to also exert a strong effect on Nrf2, thus corroborating the idea of a cross-link with Notch pathway. Among these, sulforaphane thereby induces an activation of the Nrf2/Keap1 cellular detoxification cascade by reacting with thiols of Keap1 DGR domain $[156,157]$, whereas benzo(a)pyrene(B(a)P) has been shown to inhibits carcinogenesis process in lung mouse model by promoting ROS-mediated apoptosis [158, 159]. Similar mechanism of action has been observed with Oltiplraz, known as a dithiolthione substitute able to induce phase II enzymes, which exhibited a chemoprevention effect in mouse lung adenocarcinoma [160, 161]. Resveratrol restored cigarette smoke exposure- (CSE-) depleted GSS (glutathione synthetase) levels by upregulating GCL ( $\gamma$-glutamate cysteine ligase) by reducing CSE-mediated Nrf2 modifications [162]. Intriguingly, many studies has shown that curcumin, a natural phenolic compound, which is extracted from a member of the ginger family, has a dually role as inhibitor of Notchl in osteosarcoma cells and a Nrf2 activator in normal tissues $[163,164]$.

In conclusion, the therapeutic Nrf2 targeting holds great promise for the treatment of lung cancers especially because it has documented a beneficial adjuvant effect in combination with any category of chemotherapeutics, both ROS generating and non-ROS generating agents. To date, one limitation is represented by the lack of few selective inhibitors for Nrf2 and related pathway. Another limitation is represented by the high risk of off-target toxic effects that most of the Nrf2-targeting drugs may generate due to unspecific interactions with other proteins by their electrophilic surface [165]. Nevertheless, the rational design of nonreactive small molecules directly targeting the Keapl-Nrf2 pathway appears to be the most promising strategy to limit the toxic effects often related to indirect inhibitors and increases stability and bioavailability, as compared with peptide inhibitors $[166,167]$.

\section{Concluding Remarks}

There are compelling evidences that developmental pathways, including Notch, act in concert with other pathways such as Nrf2 pathway involved in resistance to therapy, rather than as a simple on-off switch. Notch can play as tumor suppressor or oncogene depending on the cell type [168] and interestingly, Nrf2 likely functions in a similar fashion [169]. Nrf2 acts as a prosurvival factor through the expression of its cytoprotective target genes, and molecular deregulation of either Nrf2 or Keap1 is widely described in lung cancer, such as Notch family impairment. In tumors, Nrf2 and Notch signaling pathways appear to mutually regulate each other in which Notch1 is an Nrf2 target gene and Nrf2 is a RBPjk target gene. The roles of the Nrf2-Notch bidirectional interaction in driving or impeding a tumor lung phenotype are still 
unclear mainly in the context of stem cell renewal and cell proliferation and differentiation. Pharmacological interventions based on these transcription factors collaboration are demanded close with a further explorations of the regulation of this crosstalk in cellular and lung tissue context.

\section{Competing Interests}

The authors declare that they have no competing financial interests.

\section{Acknowledgments}

This work was supported by the Italian Ministry of Health Ricerca Corrente RC1503LO51 and GR Program 20102316264 to Lucia Anna Muscarella and by the AIRC/MGAF Grant 12983 (to Lucia Anna Muscarella). The authors thank Dr. Andreina Guarnieri for the English revision and Barbara Pasculli for the assistance in rewriting the paragraph "targeting Notch and Nrf2 pathways" and professional English editing.

\section{References}

[1] J. L. de la Pompa, A. Wakeham, K. M. Correia et al., "Conservation of the Notch signalling pathway in mammalian neurogenesis," Development, vol. 124, no. 6, pp. 1139-1148, 1997.

[2] E. R. Andersson and U. Lendahl, "Therapeutic modulation of Notch signalling-are we there yet?" Nature Reviews Drug Discovery, vol. 13, no. 5, pp. 357-378, 2014.

[3] S. Yamamoto, K. L. Schulze, and H. J. Bellen, "Introduction to notch signaling," Methods in Molecular Biology, vol. 1187, pp. 114, 2014.

[4] N. Wakabayashi, D. V. Chartoumpekis, and T. W. Kensler, "Crosstalk between Nrf2 and Notch signaling," Free Radical Biology and Medicine, vol. 88, pp. 158-167, 2015.

[5] S. Artavanis-Tsakonas, M. D. Rand, and R. J. Lake, "Notch signaling: cell fate control and signal integration in development," Science, vol. 284, no. 5415, pp. 770-776, 1999.

[6] N. Takebe, L. Miele, P. J. Harris et al., "Targeting Notch, Hedgehog, and Wnt pathways in cancer stem cells: clinical update," Nature Reviews Clinical Oncology, vol. 12, no. 8, pp. 445-464, 2015.

[7] I. Espinoza and L. Miele, "Notch inhibitors for cancer treatment," Pharmacology and Therapeutics, vol. 139, no. 2, pp. 95110, 2013.

[8] T. Borggrefe and F. Oswald, "The Notch signaling pathway: transcriptional regulation at Notch target genes," Cellular and Molecular Life Sciences, vol. 66, no. 10, pp. 1631-1646, 2009.

[9] E. C. Bozkulak and G. Weinmaster, "Selective use of ADAM10 and ADAM17 in activation of Notch1 signaling," Molecular and Cellular Biology, vol. 29, no. 21, pp. 5679-5695, 2009.

[10] C. Sahlgren, M. V. Gustafsson, S. Jin, L. Poellinger, and U. Lendahl, "Notch signaling mediates hypoxia-induced tumor cell migration and invasion," Proceedings of the National Academy of Sciences of the United States of America, vol. 105, no. 17, pp. 6392-6397, 2008.

[11] M. V. Gustafsson, X. Zheng, T. Pereira et al., "Hypoxia requires Notch signaling to maintain the undifferentiated cell state," Developmental Cell, vol. 9, no. 5, pp. 617-628, 2005.
[12] L. Hao, P. Rizzo, C. Osipo et al., "Notch-1 activates estrogen receptor- $\alpha$-dependent transcription via IKK $\alpha$ in breast cancer cells," Oncogene, vol. 29, no. 2, pp. 201-213, 2010.

[13] P. Hayward, T. Kalmar, and A. M. Arias, "Wnt/Notch signalling and information processing during development," Development, vol. 135, no. 3, pp. 411-424, 2008.

[14] P. Andersen, H. Uosaki, L. T. Shenje, and C. Kwon, "Noncanonical Notch signaling: emerging role and mechanism," Trends in Cell Biology, vol. 22, no. 5, pp. 257-265, 2012.

[15] A. T. Baker, A. Zlobin, and C. Osipo, "Notch-EGFR/HER2 bidirectional crosstalk in breast cancer," Frontiers in Oncology, vol. 4, article 360, 2014.

[16] K. Connolly, P. Manders, P. Earls, and R. J. Epstein, "Papillomavirus-associated squamous skin cancers following transplant immunosuppression: one Notch closer to control," Cancer Treatment Reviews, vol. 40, no. 2, pp. 205-214, 2014.

[17] E. S. Knudsen, E. M. O’Reilly, J. R. Brody, and A. K. Witkiewicz, "Genetic diversity of pancreatic ductal adenocarcinoma and opportunities for precision medicine," Gastroenterology, vol. 150, no. 1, pp. 48-63, 2016.

[18] C. Damaskos, T. Karatzas, I. D. Kostakis, L. Nikolidakis, A. Kostakis, and G. Kouraklis, "Nuclear receptors in pancreatic tumor cells," Anticancer Research, vol. 34, no. 12, pp. 6897-6911, 2014.

[19] F. E. Bertrand, C. W. Angus, W. J. Partis, and G. Sigounas, "Developmental pathways in colon cancer: crosstalk between WNT, BMP, Hedgehog and Notch," Cell Cycle, vol. 11, no. 23, pp. 4344-4351, 2012.

[20] X. Tan, U. Apte, A. Micsenyi et al., "Epidermal growth factor receptor: a novel target of the Wnt/ $\beta$-catenin pathway in liver," Gastroenterology, vol. 129, no. 1, pp. 285-302, 2005.

[21] Y. Li, J. A. Burns, C. A. Cheney et al., "Distinct expression profiles of Notch-1 protein in human solid tumors: Implications for development of targeted therapeutic monoclonal antibodies," Biologics, vol. 4, pp. 163-171, 2010.

[22] C. Talora, D. C. Sgroi, C. P. Crum, and G. Paolo Dotto, "Specific down-modulation of Notchl signaling in cervical cancer cells is required for sustained HPV-E6/E7 expression and late steps of malignant transformation," Genes and Development, vol. 16, no. 17, pp. 2252-2263, 2002.

[23] T. D. Allen, E. M. Rodriguez, K. D. Jones, and J. M. Bishop, "Activated Notch1 induces lung adenomas in mice and cooperates with Myc in the generation of lung adenocarcinoma," Cancer Research, vol. 71, no. 18, pp. 6010-6018, 2011.

[24] V. Sriuranpong, M. W. Borges, R. K. Ravi et al., "Notch signaling induces cell cycle arrest in small cell lung cancer cells," Cancer Research, vol. 61, no. 7, pp. 3200-3205, 2001.

[25] A. Baumgart, S. Seidl, P. Vlachou et al., "ADAM17 regulates epidermal growth factor receptor expression through the activation of Notchl in non-small cell lung cancer," Cancer Research, vol. 70, no. 13, pp. 5368-5378, 2010.

[26] Y. Zheng, C. C. de la Cruz, L. C. Sayles et al., "A rare population of CD24+ITGB4+Notchhi cells drives tumor propagation in NSCLC and requires Notch3 for self-renewal," Cancer Cell, vol. 24, no. 1, pp. 59-74, 2013.

[27] Q. Zheng, H. Qin, H. Zhang et al., "Notch signaling inhibits growth of the human lung adenocarcinoma cell line A549," Oncology Reports, vol. 17, no. 4, pp. 847-852, 2007.

[28] M.-M. Jin, Y.-Z. Ye, Z.-D. Qian, and Y.-B. Zhang, "Notch signaling molecules as prognostic biomarkers for non-small cell lung cancer," Oncology Letters, vol. 10, no. 5, pp. 3252-3260, 2015. 
[29] A. Di Cristofano and P. P. Pandolfi, "The multiple roles of PTEN in tumor suppression," Cell, vol. 100, no. 4, pp. 387-390, 2000.

[30] T. Palomero, M. L. Sulis, M. Cortina et al., "Mutational loss of PTEN induces resistance to NOTCH1 inhibition in T-cell leukemia," Nature Medicine, vol. 13, no. 10, pp. 1203-1210, 2007.

[31] W. H. Chappell, T. D. Green, J. D. Spengeman, J. A. McCubrey, S. M. Akula, and F. E. Bertrand, "Increased protein expression of the PTEN tumor suppressor in the presence of constitutively active Notch-1," Cell Cycle, vol. 4, no. 10, pp. 1389-1395, 2005.

[32] J. T. Whelan, S. L. Forbes, and F. E. Bertrand, "CBF-1 (RBP$\mathrm{J} \kappa$ ) binds to the PTEN promoter and regulates PTEN gene expression," Cell Cycle, vol. 6, no. 1, pp. 80-84, 2007.

[33] S. Licciulli, J. L. Avila, L. Hanlon et al., "Notch1 is required for Kras-induced lung adenocarcinoma and controls tumor cell survival via p53," Cancer Research, vol. 73, no. 19, pp. 5974-5984, 2013.

[34] A. Baumgart, P. K. Mazur, M. Anton et al., "Opposing role of Notch1 and Notch2 in a Kras(G12D)-driven murine non-small cell lung cancer model," Oncogene, vol. 34, no. 5, pp. 578-588, 2015.

[35] I. Graziani, S. Eliasz, M. A. De Marco et al., "Opposite effects of Notch-1 and Notch-2 on mesothelioma cell survival under hypoxia are exerted through the Akt pathway," Cancer Research, vol. 68, no. 23, pp. 9678-9685, 2008.

[36] W. A. Hassan, R. Yoshida, S. Kudoh, Y. Motooka, and T. Ito, "Evaluation of role of Notch3 signaling pathway in human lung cancer cells," Journal of Cancer Research and Clinical Oncology, vol. 142, no. 5, pp. 981-993, 2016.

[37] L. Zhou, S. Wu, L. Yu, X. Gong, W. Song, and Z. Cheng, "Expression of CD133 and Notch1 in non-small cell lung cancer and the clinicopathological significance," Nan Fang Yi Ke Da Xue Xue Bao, vol. 35, no. 2, pp. 196-201, 2015.

[38] T. Donnem, S. Andersen, K. Al-Shibli, S. Al-Saad, L.-T. Busund, and R. M. Bremnes, "Prognostic impact of Notch ligands and receptors in nonsmall cell lung cancer: coexpression of Notch-1 and vascular endothelial growth factor-A predicts poor survival," Cancer, vol. 116, no. 24, pp. 5676-5685, 2010.

[39] X. Yuan, H. Wu, H. Xu et al., "Meta-analysis reveals the correlation of Notch signaling with non-small cell lung cancer progression and prognosis," Scientific Reports, vol. 5, article 10338, 2015.

[40] W. A. Hassan, R. Yoshida, S. Kudoh et al., "Notch1 controls cell chemoresistance in small cell lung carcinoma cells," Thoracic Cancer, vol. 7, no. 1, pp. 123-128, 2016.

[41] P. L. Wagner, N. Kitabayashi, C. Yao-Tseng, and A. Saqi, "Combined small cell lung carcinomas: genotypic and immunophenotypic analysis of the separate morphologic components," American Journal of Clinical Pathology, vol. 131, no. 3, pp. 376382, 2009.

[42] W. A. Hassan, R. Yoshida, S. Kudoh, K. Hasegawa, K. NiimoriKita, and T. Ito, "Notchl controls cell invasion and metastasis in small cell lung carcinoma cell lines," Lung Cancer, vol. 86, no. 3, pp. 304-310, 2014.

[43] H. Wael, R. Yoshida, S. Kudoh, K. Hasegawa, K. NiimoriKita, and T. Ito, "Notch1 signaling controls cell proliferation, apoptosis and differentiation in lung carcinoma," Lung Cancer, vol. 85, no. 2, pp. 131-140, 2014.

[44] A. Singh and J. Settleman, "EMT, cancer stem cells and drug resistance: an emerging axis of evil in the war on cancer," Oncogene, vol. 29, no. 34, pp. 4741-4751, 2010.
[45] Z. Wang, Y. Li, D. Kong et al., "Acquisition of epithelialmesenchymal transition phenotype of gemcitabine-resistant pancreatic cancer cells is linked with activation of the notch signaling pathway," Cancer Research, vol. 69, no. 6, pp. 24002407, 2009.

[46] M. Xie, L. Zhang, C.-S. He et al., "Activation of Notch1 enhances epithelial-mesenchymal transition in gefitinibacquired resistant lung cancer cells," Journal of Cellular Biochemistry, vol. 113, no. 5, pp. 1501-1513, 2012.

[47] I. Espinoza and L. Miele, "Deadly crosstalk: Notch signaling at the intersection of EMT and cancer stem cells," Cancer Letters, vol. 341, no. 1, pp. 41-45, 2013.

[48] X. Yuan, H. Wu, N. Han et al., "Notch signaling and EMT in non-small cell lung cancer: biological significance and therapeutic application," Journal of Hematology and Oncology, vol. 5, no. 7, article 87, 2014.

[49] R. Schwanbeck, "The role of epigenetic mechanisms in notch signaling during development," Journal of Cellular Physiology, vol. 230, no. 5, pp. 969-981, 2015.

[50] X.-Y. Ding, J. Ding, K. Wu et al., "Cross-talk between endothelial cells and tumor via delta-like ligand 4/Notch/PTEN signaling inhibits lung cancer growth," Oncogene, vol. 31, no. 23, pp. 2899-2906, 2012.

[51] A. M. Egloff and J. R. Grandis, "Molecular pathways: contextdependent approaches to Notch targeting as cancer therapy," Clinical Cancer Research, vol. 18, no. 19, pp. 5188-5195, 2012.

[52] B. Westhoff, I. N. Colalucaa, G. D’Ario et al., "Alterations of the Notch pathway in lung cancer," Proceedings of the National Academy of Sciences of the United States, vol. 106, no. 52, pp. 22293-22298, 2009.

[53] L. Ding, G. Getz, D. A. Wheeler et al., "Somatic mutations affect key pathways in lung adenocarcinoma," Nature, vol. 455, no. 7216, pp. 1069-1075, 2008.

[54] L. Meder, K. König, L. Ozretic et al., "NOTCH, ASCL1, p53 and RB alterations define an alternative pathway driving neuroendocrine and small cell lung carcinomas," International Journal of Cancer, vol. 138, no. 4, pp. 927-938, 2016.

[55] J. George, J. S. Lim, S. J. Jang et al., "Comprehensive genomic profiles of small cell lung cancer," Nature, vol. 524, no. 7563, pp. 47-53, 2015.

[56] M. Kunnimalaiyaan and H. Chen, "Tumor suppressor role of Notch-1 signaling in neuroendocrine tumors," Oncologist, vol. 12, no. 5, pp. 535-542, 2007.

[57] D. W. Ball, "Achaete-scute homolog-1 and Notch in lung neuroendocrine development and cancer," Cancer Letters, vol. 204, no. 2, pp. 159-169, 2004.

[58] C. M. Misquitta-Ali, E. Cheng, D. O’Hanlon et al., “Global profiling and molecular characterization of alternative splicing events misregulated in lung cancer," Molecular and Cellular Biology, vol. 31, no. 1, pp. 138-150, 2011.

[59] Y.-Y. Mo, H. Tang, and L. Miele, "Notch-associated microRNAs in cancer," Current Drug Targets, vol. 14, no. 10, pp. 1157-1166, 2013.

[60] E. C. Lai, B. Tam, and G. M. Rubin, "Pervasive regulation of Drosophila Notch target genes by GY-box-, Brd-box-, and Kbox-class microRNAs," Genes \& Development, vol. 19, no. 9, pp. 1067-1080, 2005.

[61] X. Ji, Z. Wang, A. Geamanu, A. Goja, F. H. Sarkar, and S. V. Gupta, "Delta-tocotrienol suppresses Notch-1 pathway by upregulating miR-34a in nonsmall cell lung cancer cells," International Journal of Cancer, vol. 131, no. 11, pp. 2668-2677, 2012. 
[62] H. Motohashi and M. Yakamoto, "Carcinogenesis and transcriptional regulation through Maf recognition elements," Cancer Science, vol. 98, no. 2, pp. 135-139, 2007.

[63] A. Kobayashi, M.-I. Kang, H. Okawa et al., "Oxidative stress sensor Keapl functions as an adaptor for Cul3-based E3 ligase to regulate proteasomal degradation of Nrf2," Molecular and Cellular Biology, vol. 24, no. 16, pp. 7130-7139, 2004.

[64] P. Canning, F. J. Sorrell, and A. N. Bullock, "Structural basis of Keap1 interactions with Nrf2," Free Radical Biology and Medicine, vol. 88, pp. 101-107, 2015.

[65] P. Canning, C. D. O. Cooper, T. Krojer et al., "Structural basis for Cul3 protein assembly with the BTB-Kelch family of E3 ubiquitin ligases," Journal of Biological Chemistry, vol. 288, no. 11, pp. 7803-7814, 2013.

[66] K. R. Sekhar, G. Rachakonda, and M. L. Freeman, "Cysteinebased regulation of the CUL3 adaptor protein Keapl," Toxicology and Applied Pharmacology, vol. 244, no. 1, pp. 21-26, 2010.

[67] K. I. Tong, Y. Katoh, H. Kusunoki, K. Itoh, T. Tanaka, and M. Yamamoto, "Keap1 recruits Neh2 through binding to ETGE and DLG motifs: characterization of the two-site molecular recognition model," Molecular and Cellular Biology, vol. 26, no. 8, pp. 2887-2900, 2006.

[68] T. H. Rushmore, M. R. Morton, and C. B. Pickett, "The antioxidant responsive element. Activation by oxidative stress and identification of the DNA consensus sequence required for functional activity," The Journal of Biological Chemistry, vol. 266, no. 18, pp. 11632-11639, 1991.

[69] B. M. Hybertson and B. Gao, "Role of the Nrf2 signaling system in health and disease," Clinical Genetics, vol. 86, no. 5, pp. 447452, 2014

[70] D. Malhotra, E. Portales-Casamar, A. Singh et al., "Global mapping of binding sites for Nrf2 identifies novel targets in cell survival response through chip-seq profiling and network analysis," Nucleic Acids Research, vol. 38, no. 17, pp. 5718-5734, 2010.

[71] I. Gañán-Gómez, Y. Wei, H. Yang, M. C. Boyano-Adánez, and G. García-Manero, "Oncogenic functions of the transcription factor Nrf2," Free Radical Biology and Medicine, vol. 65, pp. 750764, 2013.

[72] Y. Mitsuishi, K. Taguchi, Y. Kawatani et al., "Nrf2 redirects glucose and glutamine into anabolic pathways in metabolic reprogramming," Cancer Cell, vol. 22, no. 1, pp. 66-79, 2012.

[73] S. K. Niture and A. K. Jaiswal, "Nrf2-induced antiapoptotic Bcl-xL protein enhances cell survival and drug resistance," Free Radical Biology and Medicine, vol. 57, pp. 119-131, 2013.

[74] S. K. Niture and A. K. Jaiswal, "Nrf2 protein up-regulates antiapoptotic protein $\mathrm{Bcl}-2$ and prevents cellular apoptosis," The Journal of Biological Chemistry, vol. 287, no. 13, pp. 9873-9886, 2012.

[75] K. Taguchi, H. Motohashi, and M. Yamamoto, "Molecular mechanisms of the Keap1-Nrf2 pathway in stress response and cancer evolution," Genes to Cells, vol. 16, no. 2, pp. 123-140, 2011.

[76] M. T. Landi, T. Dracheva, M. Rotunno et al., "Gene expression signature of cigarette smoking and its role in lung adenocarcinoma development and survival," PLoS ONE, vol. 3, no. 2, Article ID e1651, 2008.

[77] The Cancer Genome Atlas Research Network, "Comprehensive genomic characterization of squamous cell lung cancers," Nature, vol. 489, no. 7417, pp. 519-525, 2012.

[78] N. Rekhtman, M. C. Pietanza, M. D. Hellmann et al., "Nextgeneration sequencing of pulmonary large cell neuroendocrine carcinoma reveals small cell carcinoma-like and non-small cell carcinoma-like subsets," Clinical Cancer Research, vol. 22, no. 14, pp. 3618-3629, 2016.

[79] H. Satoh, T. Moriguchi, J. Takai, M. Ebina, and M. Yamamoto, "Nrf2 prevents initiation but accelerates progression through the kras signaling pathway during lung carcinogenesis," Cancer Research, vol. 73, no. 13, pp. 4158-4168, 2013.

[80] H. M. Leinonen, E. Kansanen, P. Pölönen, M. Heinäniemi, and A.-L. Levonen, "Dysregulation of the Keap1-Nrf2 pathway in cancer," Biochemical Society Transactions, vol. 43, no. 4, pp. 645649, 2015.

[81] Y. Huang, W. Li, Z.-Y. Su, and A.-N. T. Kong, “The complexity of the Nrf2 pathway: beyond the antioxidant response," Journal of Nutritional Biochemistry, vol. 26, no. 12, pp. 1401-1413, 2015.

[82] S. Murakami and H. Motohashi, "Roles of Nrf2 in cell proliferation and differentiation," Free Radical Biology and Medicine B, vol. 88, pp. 168-178, 2015.

[83] H. Yang, W. Wang, Y. Zhang et al., "The role of NF-E2related factor 2 in predicting chemoresistance and prognosis in advanced non-small-cell lung cancer," Clinical Lung Cancer, vol. 12, no. 3, pp. 166-171, 2011.

[84] L. M. Solis, C. Behrens, W. Dong et al., "Nrf2 and Keap1 abnormalities in non-small cell lung carcinoma and association with clinicopathologic features," Clinical Cancer Research, vol. 16, no. 14, pp. 3743-3753, 2010.

[85] D. W. Cescon, D. She, S. Sakashita et al., "NRF2 pathway activation and adjuvant chemotherapy benefit in lung squamous cell carcinoma," Clinical Cancer Research, vol. 21, no. 11, pp. 24992505, 2015.

[86] L. A. Muscarella, P. Parrella, V. D’Alessandro et al., "Frequent epigenetics inactivation of KEAP1 gene in non-small cell lung cancer," Epigenetics, vol. 6, no. 6, pp. 710-719, 2011.

[87] T. Takahashi, M. Sonobe, T. Menju et al., "Mutations in Keap1 are a potential prognostic factor in resected non-small cell lung cancer," Journal of Surgical Oncology, vol. 101, no. 6, pp. 500-506, 2010.

[88] M. S. Degese, J. E. Mendizabal, N. A. Gandini et al., "Expression of heme oxygenase- 1 in non-small cell lung cancer (NSCLC) and its correlation with clinical data," Lung Cancer, vol. 77, no. 1, pp. 168-175, 2012.

[89] J.-R. Tsai, H.-M. Wang, P.-L. Liu et al., "High expression of heme oxygenase- 1 is associated with tumor invasiveness and poor clinical outcome in non-small cell lung cancer patients," Cellular Oncology, vol. 35, no. 6, pp. 461-471, 2012.

[90] J. M. Kolesar, S. C. Pritchard, K. M. Kerr, K. Kim, M. C. Nicolson, and H. McLeod, "Evaluation of NQO1 gene expression and variant allele in human NSCLC tumors and matched normal lung tissue," International Journal of Oncology, vol. 21, no. 5, pp. 1119-1124, 2002.

[91] J. M. Kolesar, S. E. Dahlberg, S. Marsh et al., "The NQO1* $2 /^{*} 2$ polymorphism is associated with poor overall survival in patients following resection of stages II and IIIa non-small cell lung cancer," Oncology Reports, vol. 25, no. 6, pp. 1765-1772, 2011.

[92] Z. Li, Y. Zhang, T. Jin et al., "NQO1 protein expression predicts poor prognosis of non-small cell lung cancers," BMC Cancer, vol. 15, no. 1, article 207, 2015.

[93] Z. Qian, T. Zhou, C. I. Gurguis et al., "Nuclear factor, erythroid 2-like 2-associated molecular signature predicts lung cancer survival," Scientific Reports, vol. 5, article 16889, 2015. 
[94] M. E. Abazeed, D. J. Adams, K. E. Hurov et al., "Integrative radiogenomic profiling of squamous cell lung cancer," Cancer Research, vol. 73, no. 20, pp. 6289-6298, 2013.

[95] S. Tao, S. Wang, S. J. Moghaddam et al., "Oncogenic KRAS confers chemoresistance by upregulating NRF2," Cancer Research, vol. 74, no. 24, pp. 7430-7441, 2014.

[96] P. Y. Yip, “Phosphatidylinositol 3-kinase-AKT-mammalian target of rapamycin (PI3K-Akt-mTOR) signaling pathway in nonsmall cell lung cancer," Translational Lung Cancer Research, vol. 4, no. 2, pp. 165-176, 2015.

[97] S. Lee, M.-J. Lim, M.-H. Kim et al., "An effective strategy for increasing the radiosensitivity of Human lung Cancer cells by blocking Nrf2-dependent antioxidant responses," Free Radical Biology and Medicine, vol. 53, no. 4, pp. 807-816, 2012.

[98] T. D. Clay, P. A. Russell, H. Do et al., "Associations between the IASLC/ATS/ERS lung adenocarcinoma classification and EGFR and KRAS mutations," Pathology, vol. 48, no. 1, pp. 17-24, 2016.

[99] B. Lee, T. Lee, S. H. Lee, Y. L. Choi, and J. Han, "Clinicopathologic characteristics of EGFR, KRAS, and ALK alterations in 6,595 lung cancers," Oncotarget, vol. 7, no. 17, pp. 23874-23884, 2016.

[100] G. M. DeNicola, F. A. Karreth, T. J. Humpton et al., "Oncogeneinduced Nrf2 transcription promotes ROS detoxification and tumorigenesis," Nature, vol. 475, no. 7354, pp. 106-110, 2011.

[101] A. Singh, V. Misra, R. K. Thimmulappa et al., "Dysfunctional KEAP1-NRF2 interaction in non-small-cell lung cancer," PLoS Medicine, vol. 3, no. 10, article e420, 2006.

[102] S. K. Niture and A. K. Jaiswal, "Prothymosin- $\alpha$ mediates nuclear import of the INrf2/ Cul3.Rbxl complex to degrade nuclear Nrf2," The Journal of Biological Chemistry, vol. 284, no. 20, pp. 13856-13868, 2009.

[103] O.-H. Lee, A. K. Jain, V. Papusha, and A. K. Jaiswal, "An autoregulatory loop between stress sensors INrf2 and Nrf2 controls their cellular abundance," Journal of Biological Chemistry, vol. 282, no. 50, pp. 36412-36420, 2007.

[104] Z. Sun, S. Zhang, J. Y. Chan, and D. D. Zhang, "Keapl controls postinduction repression of the Nrf2-mediated antioxidant response by escorting nuclear export of Nrf2," Molecular and Cellular Biology, vol. 27, no. 18, pp. 6334-6349, 2007.

[105] Y. Mitsuishi, H. Motohashi, and M. Yamamoto, "The Keap1-Nrf2 system in cancers: stress response and anabolic metabolism," Frontiers in Oncology, vol. 2, article 200, 2012.

[106] T. Shibata, T. Ohta, K. I. Tong et al., "Cancer related mutations in NRF2 impair its recognition by Keap1-Cul3 E3 ligase and promote malignancy," Proceedings of the National Academy of Sciences of the United States of America, vol. 105, no. 36, pp. 13568-13573, 2008.

[107] Y. R. Kim, J. E. Oh, M. S. Kim et al., "Oncogenic NRF2 mutations in squamous cell carcinomas of oesophagus and skin," Journal of Pathology, vol. 220, no. 4, pp. 446-451, 2010.

[108] Clinical Lung Cancer Genome Project (CLCGP) and Network Genomic Medicine (NGM), "A genomics-based classification of human lung tumors," Science Translational Medicine, vol. 5, no. 209, p. 209ra153, 2013.

[109] Y. Kim, P. S. Hammerman, J. Kim et al., "Integrative and comparative genomic analysis of lung squamous cell carcinomas in East Asian patients," Journal of Clinical Oncology, vol. 32, no. 2, pp. 121-128, 2014.

[110] Q. K. Li, A. Singh, S. Biswal, F. Askin, and E. Gabrielson, "KEAP1 gene mutations and NRF2 activation are common in pulmonary papillary adenocarcinoma," Journal of Human Genetics, vol. 56, no. 3, pp. 230-234, 2011.
[111] J. M. Kaufman, J. M. Amann, K. Park et al., "LKB1 loss induces characteristic patterns of gene expression in human tumors associated with NRF2 activation and attenuation of PI3K-AKT," Journal of Thoracic Oncology, vol. 9, no. 6, pp. 794-804, 2014.

[112] L. Fernandez-Cuesta, M. Peifer, X. Lu et al., "Abstract 1531: crossentity mutation analysis of lung neuroendocrine tumors sheds light into their molecular origin and identifies new therapeutic targets," Cancer Research, vol. 74, no. 19, supplement, 2014.

[113] Z. Li, L. Xu, N. Tang et al., "The polycomb group protein EZH2 inhibits lung cancer cell growth by repressing the transcription factor Nrf2," FEBS Letters, vol. 588, no. 17, pp. 3000-3007, 2014.

[114] M. T. M. Van Jaarsveld, J. Helleman, A. W. M. Boersma et al., "miR-141 regulates KEAP1 and modulates cisplatin sensitivity in ovarian cancer cells," Oncogene, vol. 32, no. 36, pp. 4284-4293, 2013.

[115] B. N. Chorley, M. R. Campbell, X. Wang et al., "Identification of novel NRF2-regulated genes by ChIP-Seq: influence on retinoid X receptor alpha," Nucleic Acids Research, vol. 40, no. 15, pp. 7416-7429, 2012.

[116] N. M. Shah, S. A. Rushworth, M. Y. Murray, K. M. Bowles, and D. J. MacEwan, "Understanding the role of NRF2-regulated miRNAs in human malignancies," Oncotarget, vol. 4, no. 8, pp. 1130-1142, 2013.

[117] N. Duru, R. Gernapudi, Y. Zhang et al., "NRF2/miR-140 signaling confers radioprotection to human lung fibroblasts," Cancer Letters, vol. 369, no. 1, pp. 184-191, 2015.

[118] T. Murray-Stewart, C. L. Hanigan, P. M. Woster, L. J. Marton, and R. A. Casero Jr., "Histone deacetylase inhibition overcomes drug resistance through a miRNA-dependent mechanism," Molecular Cancer Therapeutics, vol. 12, no. 10, pp. 2088-2099, 2013.

[119] Y. Guo, S. Yu, C. Zhang, and A. N. Kong, "Epigenetic regulation of Keap1-Nrf2 signaling," Free Radical Biology \& Medicine, vol. 88, part B, pp. 337-349, 2015.

[120] R. Wang, J. An, F. Ji, H. Jiao, H. Sun, and D. Zhou, "Hypermethylation of the Keapl gene in human lung cancer cell lines and lung cancer tissues," Biochemical and Biophysical Research Communications, vol. 373, no. 1, pp. 151-154, 2008.

[121] X. Liu, C. Sun, B. Liu et al., "Genistein mediates the selective radiosensitizing effect in NSCLC A549 cells via inhibiting methylation of the keapl gene promoter region," Oncotarget, vol. 7, no. 19, pp. 27267-27279, 2016.

[122] Z. Chen, X. Ye, N. Tang et al., "The histone acetylranseferase hMOF acetylates Nrf2 and regulates anti-drug responses in human non-small cell lung cancer," British Journal of Pharmacology, vol. 171, no. 13, pp. 3196-3211, 2014.

[123] A. Singh, C. Happel, S. K. Manna et al., "Transcription factor NRF2 regulates miR-1 and miR-206 to drive tumorigenesis," The Journal of Clinical Investigation, vol. 123, no. 7, pp. 2921-2934, 2013.

[124] C. Xia, X. Bai, X. Hou et al., "Cryptotanshinone reverses cisplatin resistance of human lung carcinoma A549 cells through down-regulating Nrf2 pathway," Cellular Physiology and Biochemistry, vol. 37, no. 2, pp. 816-824, 2015.

[125] X. Tang, H. Wang, L. Fan et al., "Luteolin inhibits Nrf2 leading to negative regulation of the Nrf2/ARE pathway and sensitization of human lung carcinoma A549 cells to therapeutic drugs," Free Radical Biology and Medicine, vol. 50, no. 11, pp. 1599-1609, 2011.

[126] S. Chian, R. Thapa, Z. Chi, X. J. Wang, and X. Tang, "Luteolin inhibits the Nrf2 signaling pathway and tumor growth in vivo," Biochemical and Biophysical Research Communications, vol. 447, no. 4, pp. 602-608, 2014. 
[127] S. Homma, Y. Ishii, Y. Morishima et al., "Nrf2 enhances cell proliferation and resistance to anticancer drugs in human lung cancer," Clinical Cancer Research, vol. 15, no. 10, pp. 3423-3432, 2009.

[128] S. Vartanian, T. P. Ma, J. Lee et al., "Application of mass spectrometry profiling to establish brusatol as an inhibitor of global protein synthesis," Molecular \& Cellular Proteomics, vol. 15, no. 4, pp. 1220-1231, 2016.

[129] K. Wang, T. Zhang, Q. Dong, E. C. Nice, C. Huang, and Y. Wei, "Redox homeostasis: the linchpin in stem cell self-renewal and differentiation," Cell Death and Disease, vol. 4, no. 3, article e537, 2013.

[130] C. E. Hochmuth, B. Biteau, D. Bohmann, and H. Jasper, "Redox regulation by keap1 and Nrf2 controls intestinal stem cell proliferation in drosophila," Cell Stem Cell, vol. 8, no. 2, pp. 188199, 2011.

[131] Y.-Y. Jang and S. J. Sharkis, "A low level of reactive oxygen species selects for primitive hematopoietic stem cells that may reside in the low-oxygenic niche," Blood, vol. 110, no. 8, pp. 3056-3063, 2007.

[132] J. E. Le Belle, N. M. Orozco, A. A. Paucar et al., "Proliferative neural stem cells have high endogenous ROS levels that regulate self-renewal and neurogenesis in a PI3K/Akt-dependant manner," Cell Stem Cell, vol. 8, no. 1, pp. 59-71, 2011.

[133] J. J. Tsai, J. A. Dudakov, K. Takahashi et al., "Nrf2 regulates haematopoietic stem cell function," Nature Cell Biology, vol. 15, no. 3, pp. 309-316, 2013.

[134] N. Wakabayashi, S. Shin, S. L. Slocum et al., "Regulation of Notch1 signaling by Nrf2: implications for tissue regeneration," Science Signaling, vol. 3, no. 130, article ra52, 2010.

[135] Y. Zong, A. Panikkar, J. Xu et al., "Notch signaling controls liver development by regulating biliary differentiation," Development, vol. 136, no. 10, pp. 1727-1739, 2009.

[136] N. Wakabayashi, J. J. Skoko, D. V. Chartoumpekis et al., "NotchNrf2 axis: regulation of Nrf2 gene expression and cytoprotection by notch signaling," Molecular and Cellular Biology, vol. 34, no. 4, pp. 653-663, 2014.

[137] E. Barreiro, V. I. Peinado, J. B. Galdiz et al., "Cigarette smokeinduced oxidative stress: a role in chronic obstructive pulmonary disease skeletal muscle dysfunction," American Journal of Respiratory and Critical Care Medicine, vol. 182, no. 4, pp. 477488, 2010.

[138] M. K. Paul, B. Bisht, D. O. Darmawan et al., "Dynamic changes in intracellular ROS levels regulate airway basal stem cell homeostasis through Nrf2-dependent notch signaling," Cell Stem Cell, vol. 15, no. 2, pp. 199-214, 2014.

[139] C. D. Peacock and D. N. Watkins, "Cancer stem cells and the ontogeny of lung cancer," Journal of Clinical Oncology, vol. 26, no. 17, pp. 2883-2889, 2008.

[140] N. Wakabayashi, S. L. Slocum, J. J. Skoko, S. Shin, and T. W. Kensler, "When NRF2 talks, who's listening?" Antioxidants \& Redox Signaling, vol. 13, no. 11, pp. 1649-1663, 2010.

[141] Q. Zhao, A. Mao, J. Yan et al., "Downregulation of Nrf2 promotes radiation-induced apoptosis through Nrf2 mediated Notch signaling in non-small cell lung cancer cells," International Journal of Oncology, vol. 48, no. 2, pp. 765-773, 2016.

[142] M. S. Lawrence, P. Stojanov, C. H. Mermel et al., "Discovery and saturation analysis of cancer genes across 21 tumour types," Nature, vol. 505, no. 7484, pp. 495-501, 2014.

[143] N. Takebe, D. Nguyen, and S. X. Yang, "Targeting Notch signaling pathway in cancer: clinical development advances and challenges," Pharmacology and Therapeutics, vol. 141, no. 2, pp. 140-149, 2014.

[144] X. Yuan, H. Wu, H. Xu et al., "Notch signaling: an emerging therapeutic target for cancer treatment," Cancer Letters, vol. 369, no. 1, pp. 20-27, 2015.

[145] Y. Wu, C. Cain-Hom, L. Choy et al., "Therapeutic antibody targeting of individual Notch receptors," Nature, vol. 464, no. 7291, pp. 1052-1057, 2010.

[146] R. Olsauskas-Kuprys, A. Zlobin, and C. Osipo, "Gamma secretase inhibitors of Notch signaling," OncoTargets and Therapy, vol. 6, pp. 943-955, 2013.

[147] W. A. Messersmith, G. I. Shapiro, J. M. Cleary et al., "A phase I, dose-finding study in patients with advanced solid malignancies of the oral $\gamma$-secretase inhibitor PF-03084014," Clinical Cancer Research, vol. 21, no. 1, pp. 60-67, 2015.

[148] W.-C. Yen, M. M. Fischer, F. Axelrod et al., "Targeting notch signaling with a Notch2/Notch3 antagonist (tarextumab) inhibits tumor growth and decreases tumor-initiating cell frequency," Clinical Cancer Research, vol. 21, no. 9, pp. 2084-2095, 2015.

[149] M. C. Pietanza, L. A. Byers, J. D. Minna, and C. M. Rudin, "Small cell lung cancer: will recent progress lead to improved outcomes?" Clinical Cancer Research, vol. 21, no. 10, pp. 22442255, 2015.

[150] A. Ahmad, W. A. Sakr, and K. M. Rahman, "Novel targets for detection of cancer and their modulation by chemopreventive natural compounds," Frontiers in Bioscience, vol. 4, pp. 410-425, 2012.

[151] S. N. Pinchot, R. Jaskula-Sztul, L. Ning et al., "Identification and validation of Notch pathway activating compounds through a novel high-throughput screening method," Cancer, vol. 117, no. 7, pp. 1386-1398, 2011.

[152] D. Subramaniam, N. D. Nicholes, A. Dhar et al., "3,5-bis(2,4difluorobenzylidene)-4-piperidone, a novel compound that affects pancreatic cancer growth and angiogenesis," Molecular Cancer Therapeutics, vol. 10, no. 11, pp. 2146-2156, 2011.

[153] M. C. Jaramillo and D. D. Zhang, "The emerging role of the Nrf2-Keap1 signaling pathway in cancer," Genes \& Development, vol. 27, no. 20, pp. 2179-2191, 2013.

[154] J. W. Xiu, J. D. Hayes, C. J. Henderson, and C. R. Wolf, "Identification of retinoic acid as an inhibitor of transcription factor Nrf2 through activation of retinoic acid receptor alpha," Proceedings of the National Academy of Sciences of the United States of America, vol. 104, no. 49, pp. 19589-19594, 2007.

[155] S. H. Ki, I. J. Cho, D. W. Choi, and S. G. Kim, "Glucocorticoid Receptor (GR)-associated SMRT binding to C/EBP $\beta$ TAD and Nrf2 Neh4/5: role of SMRT recruited to GR in GSTA2 gene repression," Molecular and Cellular Biology, vol. 25, no. 10, pp. 4150-4165, 2005.

[156] L. Yang, D. L. Palliyaguru, and T. W. Kensler, "Frugal chemoprevention: targeting Nrf2 with foods rich in sulforaphane," Seminars in Oncology, vol. 43, no. 1, pp. 146-153, 2016.

[157] F. Hong, M. L. Freeman, and D. C. Liebler, "Identification of sensor cysteines in human Keapl modified by the cancer chemopreventive agent sulforaphane," Chemical Research in Toxicology, vol. 18, no. 12, pp. 1917-1926, 2005.

[158] D. Kalpana Deepa Priya, R. Gayathri, and D. Sakthisekaran, "Role of sulforaphane in the anti-initiating mechanism of lung carcinogenesis in vivo by modulating the metabolic activation and detoxification of benzo(a)pyrene," Biomedicine and Pharmacotherapy, vol. 65, no. 1, pp. 9-16, 2011. 
[159] G. H. Jo, G.-Y. Kim, W.-J. Kim, K. Y. Park, and Y. H. Choi, "Sulforaphane induces apoptosis in T24 human urinary bladder cancer cells through a reactive oxygen species-mediated mitochondrial pathway: the involvement of endoplasmic reticulum stress and the Nrf2 signaling pathway," International Journal of Oncology, vol. 45, no. 4, pp. 1497-1506, 2014.

[160] S. H. Choi, Y. M. Kim, J. M. Lee, and S. G. Kim, "Antioxidant and mitochondrial protective effects of oxidized metabolites of oltipraz," Expert Opinion on Drug Metabolism and Toxicology, vol. 6, no. 2, pp. 213-224, 2010.

[161] S. Sharma, P. Gao, and V. E. Steele, "The chemopreventive efficacy of inhaled oltipraz particulates in the B[a]P-induced A/J mouse lung adenoma model," Carcinogenesis, vol. 27, no. 8, pp. 1721-1727, 2006.

[162] A. Kode, S. Rajendrasozhan, S. Caito, S.-R. Yang, I. L. Megson, and I. Rahman, "Resveratrol induces glutathione synthesis by activation of $\mathrm{Nrf} 2$ and protects against cigarette smokemediated oxidative stress in human lung epithelial cells," American Journal of Physiology_Lung Cellular and Molecular Physiology, vol. 294, no. 3, pp. L478-L488, 2008.

[163] R. Garg, S. Gupta, and G. B. Maru, "Dietary curcumin modulates transcriptional regulators of phase I and phase II enzymes in benzo[a]pyrene-treated mice: mechanism of its anti-initiating action," Carcinogenesis, vol. 29, no. 5, pp. 10221032, 2008.

[164] Y. Li, J. Zhang, D. Ma et al., "Curcumin inhibits proliferation and invasion of osteosarcoma cells through inactivation of Notch1 signaling," The FEBS Journal, vol. 279, no. 12, pp. 2247-2259, 2012.

[165] S. Magesh, Y. Chen, and L. Hu, "Small molecule modulators of Keap1-Nrf2-ARE pathway as potential preventive and therapeutic agents," Medicinal Research Reviews, vol. 32, no. 4, pp. 687726, 2012.

[166] L. Hu, S. Magesh, L. Chen et al., "Discovery of a small-molecule inhibitor and cellular probe of Keap1-Nrf2 protein-protein interaction," Bioorganic and Medicinal Chemistry Letters, vol. 23, no. 10, pp. 3039-3043, 2013.

[167] Z.-Y. Jiang, M.-C. Lu, L.-L. Xu et al., "Discovery of potent Keap1Nrf2 protein-protein interaction inhibitor based on molecular binding determinants analysis," Journal of Medicinal Chemistry, vol. 57, no. 6, pp. 2736-2745, 2014.

[168] F. Radtke and K. Raj, "The role of Notch in tumorigenesis: oncogene or tumour suppressor," Nature Reviews Cancer, vol. 3, no. 10, pp. 756-767, 2003.

[169] A. Lau, N. F. Villeneuve, Z. Sun, P. K. Wong, and D. D. Zhang, "Dual roles of Nrf2 in cancer," Pharmacological Research, vol. 58, no. 5-6, pp. 262-270, 2008. 


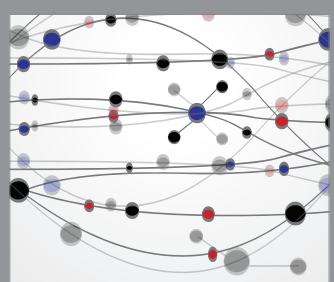

The Scientific World Journal
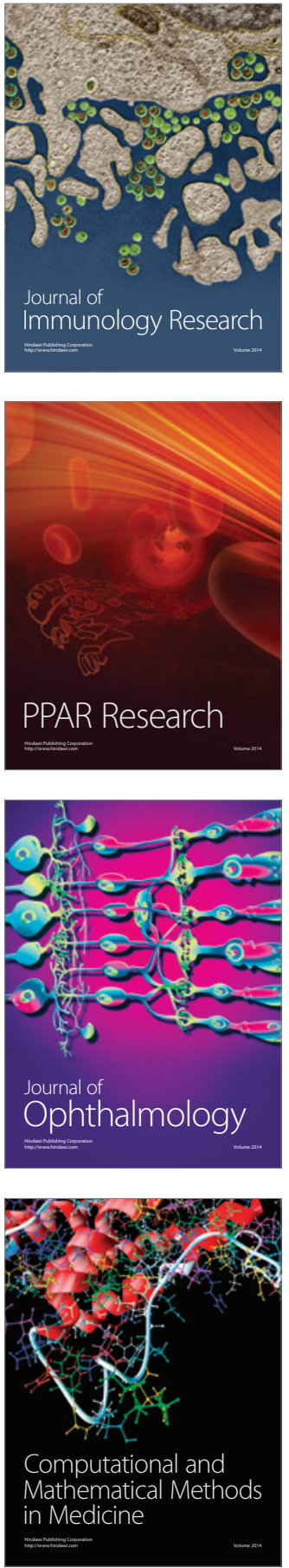

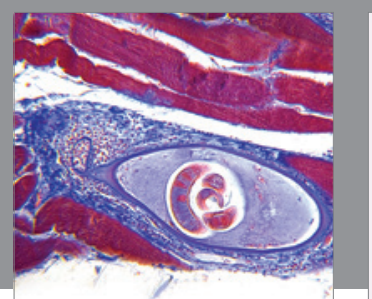

Gastroenterology Research and Practice

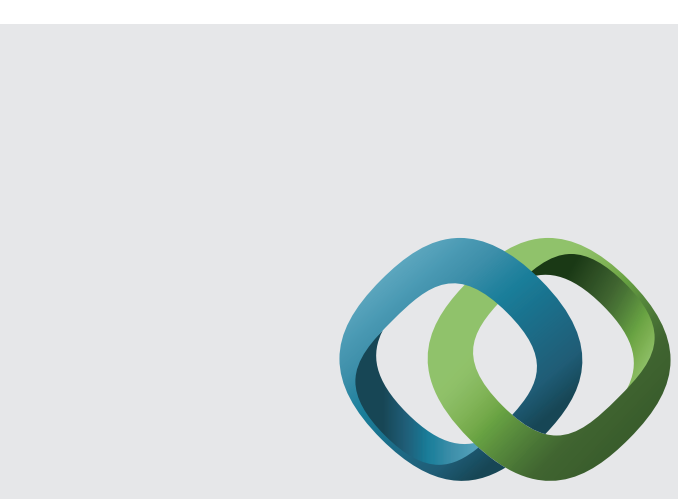

\section{Hindawi}

Submit your manuscripts at

http://www.hindawi.com
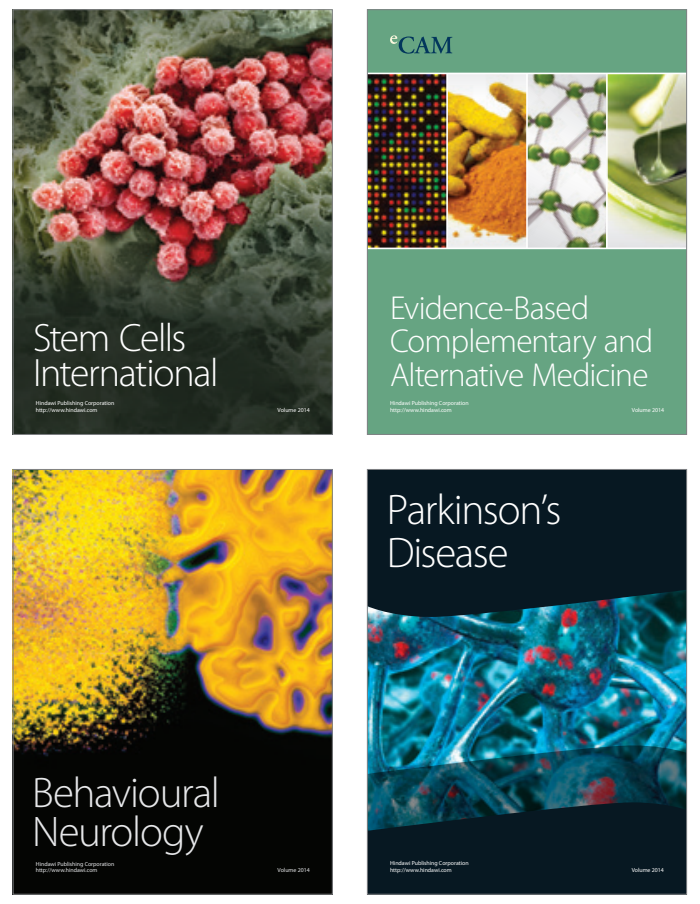
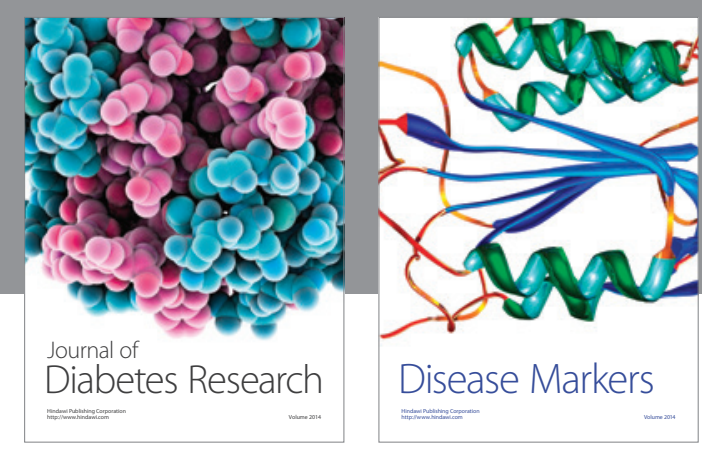

Disease Markers
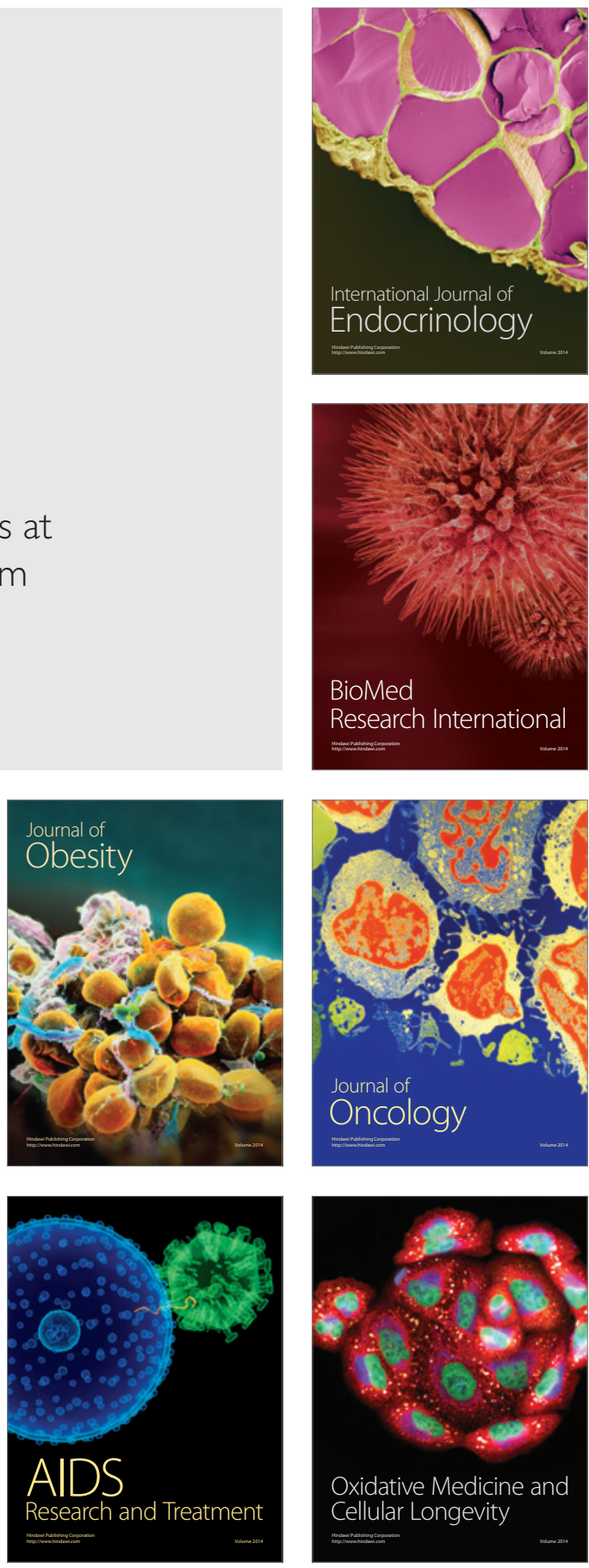